\title{
HUMIC ACID BASED BIOPOLYMERIC MEMBRANE FOR EFFECTIVE REMOVAL OF METHYLENE BLUE AND RHODAMINE B
}

\author{
Seema S. Shenvi ${ }^{\mathrm{a}}$, Arun M. Isloor ${ }^{\mathrm{a}^{*}}$, Ahmad F. Ismail ${ }^{\mathrm{b}}$, Simon J. Shilton ${ }^{\mathrm{c}}$ and Amir Al Ahmed ${ }^{\mathrm{d}}$ \\ ${ }^{a}$ Membrane Technology Laboratory, Department of Chemistry, National Institute of Technology \\ Karnataka, Surathkal, Mangalore 575 025, INDIA \\ ${ }^{b}$ Advanced Membrane Technology Research Center (AMTEC), Universiti Teknologi Malaysia, \\ 81310 Skudai, Johor Bahru, Malaysia \\ ${ }^{\mathrm{c}}$ Department of Chemical and Process Engineering, University of Strathclyde, James \\ Weir Building, 75 Montrose Street, Glasgow, G1 1XJ, Scotland. \\ ${ }^{d}$ Center of Research Excellence in Renewable Energy, King Fahd University of Petroleum and Minerals, \\ Dhahran-31261, Saudi Arabia
}

\begin{abstract}
:
Humic acid was immobilized on a polypropylene supported sodium alginate/hydroxyethyl cellulose blend membrane in the current work. The adsorption property of this membrane for the removal of cationic dyes, namely, methylene blue (MB) and rhodamine B $(\mathrm{RhB})$ was extensively studied. Batch-adsorption experiments were conducted to investigate the adsorption behavior of dyes on the membrane with variation in adsorbent mass, initial dye concentration, $\mathrm{pH}$, time and temperature. The membranes were characterized by Scanning electron microscopy (SEM), Energy dispersive X-ray analysis (EDX), Fourier transform infrared spectroscopy (FTIR) and Atomic force microscopy (AFM). Prepared membranes showed more than $98 \%$ removal capacity for both dyes under optimal conditions. Kinetic experiments revealed that, the pseudo second order model exhibited best correlation with the adsorption data. DubininRadushkevich model indicated that, the adsorption of dyes onto the membrane surface was by simple physisorption. The membrane was easily regenerated by simple acid treatment and its efficiency remained significant even after four adsorption cycles.
\end{abstract}

Key words: Humic acid, biopolymeric, dyes, adsorption, reusability.

Author for correspondence: E-mail address: isloor@yahoo.com, Fax: 918242474033 


\section{Introduction}

Extensive industrialization has resulted in severe water contamination of water bodies in addition to lack of treatment of industrial discharge. A number of contaminants such as pesticides, toxic metals, dyes, suspended solids, fertilizers, etc. are known to pollute the aesthetic quality of water. ${ }^{1-2}$ Stringent regulations on the quality of water have made the treatment of these pollutants very essential before their consumption for domestic purposes. Dyes are commonly used in textile, pharmaceutical, food, tanning and paper industry. ${ }^{3-5}$ Removal of dyes from water sources is necessary because of their recalcitrant, toxic and non-biodegradable nature. ${ }^{6-7}$ Presence of dye affects chemical oxygen demand (COD) of the effluent and sunlight penetration, which has a detrimental effect on aquatic life. ${ }^{8}$ Basic dyes have such high color intensity that, even at trace levels they impart color to water, making it undesirable for consumption. Although the effect of basic dyes such as methylene blue (MB) and rhodamine $B(R h B)$ are not as hazardous as azo or reactive dyes, acute exposure to the same may however result in serious health issues. MB can cause increased heart rate on inhalation; ingestion through mouth may lead to vomiting, nausea, jaundice, tissue necrosis and quadriplegia. ${ }^{3,9} \mathrm{RhB}$ is commonly used as a staining dye in biotechnology. It is known to cause irritation of skin, eyes and respiratory tract in addition to neurotoxicity and carcinogenicity. ${ }^{10-11}$ Removal of these dyes by various techniques have been studied in the past, amongst which adsorption is the simplest and widely adopted technology. ${ }^{12-13}$ Other techniques include flocculation/coagulation, membrane filtration, photo degradation, ozonation, and chemical and/or biological degradation.

Adsorption technique is more desirable and economical if the adsorbents used for dye removal process are cheaper, non-toxic, and biodegradable in nature. Keeping this in view, more and more number of researchers are experimenting to come up with better alternatives to the existing options. Humic acid is (HA) one such material which has the capacity to bind to diverse nature of chemical compounds and materials due to the presence of functional carboxylic and phenolic groups. ${ }^{14}$ In addition to imparting odor and color to water, HA is capable of reacting with chlorine in water to produce trihalomethanes which are potential carcinogenic agents. ${ }^{15}$ The presence of these groups lead to structural and chemical changes in HA, thereby making it toxic in nature. The binding capacity of carboxylic and phenolic groups responsible for HA toxicity has been used to address dye removal problem in our current work. The outstanding ability of 
HA for effective removal of pollutants from water has been studied previously. ${ }^{16-19}$ The positively charged basic dyes can be easily adsorbed by the negatively charged HA when the carboxylic and phenolic groups in HA are deprotonated in weakly acidic or basic media. However, the water-soluble property of HA necessitates its immobilization on water-insoluble matrix. For immobilization, sodium alginate (SA) and hydroxyethyl cellulose (HEC) biopolymeric membrane crosslinked with glutaraldehyde (GA) was used. SA and HEC are water-soluble biopolymers that form compatible blends and are capable of forming film. ${ }^{20} \mathrm{HA}$ immobilization on this blend has been reported by Chen et al. for removal of heavy metals. ${ }^{21-22}$ However, no studies have been carried out on this adsorbent membrane for removal of dyes.

The objective of this work is to carry out detailed investigation on the use of $\mathrm{SA} / \mathrm{HEC} / \mathrm{HA}$ composite membrane crosslinked with GA for the removal of MB and $\mathrm{RhB}$. The parameters affecting the dye adsorption, namely, $\mathrm{pH}$, temperature, adsorbent dosage and initial concentration have been thoroughly investigated. The adsorption data was tested for four isotherm models including Langmuir, Freundlich, Temkin and Dubinin-Radushkevich. The kinetic modeling of the adsorption process was also tested using different kinetic models and their mechanism was discussed. The thermodynamic parameters were determined to find the nature and feasibility of the process. Lastly, the reusability of the membrane was tested for both the dyes.

\section{Experimental}

\subsection{Materials}

2-Hydroxyethyl cellulose (HEC) $\left(\mathrm{M}_{\mathrm{w}} \sim 250,000 \mathrm{~g} / \mathrm{mol}\right)$, methylene blue (MB) $\left(\mathrm{M}_{\mathrm{w}} \sim 373.9\right.$ $\mathrm{g} / \mathrm{mol})$ and rhodamine $\mathrm{B}(\mathrm{RhB})\left(\mathrm{M}_{\mathrm{w}} \sim 479.01 \mathrm{~g} / \mathrm{mol}\right)$ was procured form Sigma Aldrich Co. Sodium Alginate (SA) and sodium salt of humic acid (HA) used for preparation of membrane was obtained from Himedia, Mumbai. Glutaraldehyde (GA) (25\% solution) was obtained from Merck India Ltd. $\mathrm{NaOH}$ and $\mathrm{HCl}$ required for $\mathrm{pH}$ studies were of analytical grade. All the chemicals were used without further purification. Structure of MB and RhB are given in Figure1. 

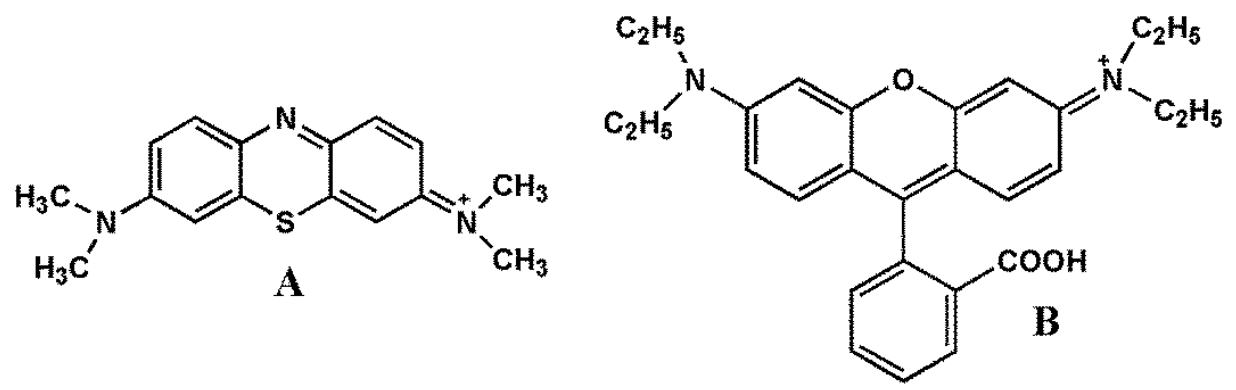

Figure 1 Structure of A) Methylene blue and B) Rhodamine B

\subsection{Membrane preparation}

The polymer solution comprising the membrane had an overall composition of $3 \mathrm{wt} . \%$. SA (2.2 g), HEC (0.4 g), HA (0.4 g) was dissolved in $100 \mathrm{~mL}$ of distilled water for $24 \mathrm{~h}$ at room temperature $\left(30 \pm 1{ }^{\circ} \mathrm{C}\right)$. After its dissolution, the polymer solution was subjected to centrifugation at $1500 \mathrm{rpm}$ for $0.5 \mathrm{~h}$ so as to remove undissolved particles. This solution was then poured onto a glass plate to which a polypropylene support was already pasted using a double sided tape. Handling of the adsorbent membrane became relatively convenient and easy as a result of the strong polypropylene support. The membrane was then dried in an oven at 40 ${ }^{\circ} \mathrm{C}$ for $24 \mathrm{~h}$, after which it was crosslinked with GA. For crosslinking, the dried membrane was immersed in a solution containing $70 \%$ aqueous methanol, $2.5 \mathrm{wt} . \%$ conc. $\mathrm{HCl}$ and $2.5 \mathrm{wt} \% \mathrm{GA}$ for $4 \mathrm{~h}$ at $27^{\circ} \mathrm{C}$. The crosslinked membrane was then thoroughly washed with distilled water and dried overnight at $40{ }^{\circ} \mathrm{C}$ in a vacuum oven before subjecting it to characterization and dye removal studies.

\subsection{Characterization}

\subsubsection{Determination of point of zero charge of membrane}

Zero point charge $\left(\mathrm{P}_{\mathrm{zc}}\right)$ of the membrane explains the condition at which the surface of the membrane has zero charge density. $\mathrm{P}_{\mathrm{zc}}$ was determined as mentioned in the literature. ${ }^{22} 25$ $\mathrm{mL}$ of $0.1 \mathrm{M} \mathrm{NaCl}$ solution was transferred in a series of $100 \mathrm{~mL}$ Erlenmeyer flasks whose $\mathrm{pH}$ was adjusted from 1 to 9 by the addition of either $0.1 \mathrm{M} \mathrm{HCl}$ or $0.1 \mathrm{M} \mathrm{NaOH}$ solutions. The $\mathrm{pH}$ of the solution was measured using EQUIP-TRONIC pH meter (Model EQ-610). The initial pH of these solutions was noted as $\mathrm{pH}_{1} .0 .1 \mathrm{~g}$ adsorbent was added to each of the flasks. The flasks were placed on an orbital shaker (Scigenic Biotech) at room temperature, and at $150 \mathrm{rpm}$ till no difference in $\mathrm{pH}$ values was observed between two successive readings. The equilibrium $\mathrm{pH}$ 
value was noted as $\mathrm{pH}_{\mathrm{e}}$, which was used to calculate $\Delta \mathrm{pH}\left(\mathrm{pH}_{1}-\mathrm{pH}_{\mathrm{e}}\right)$. Graph of $\Delta \mathrm{pH}$ against $\mathrm{pH}_{1}$ gave the $\mathrm{P}_{\mathrm{zc}}$ value at which the $\Delta \mathrm{pH}$ reads zero. The experiment was performed twice and the mean value was reported.

\subsubsection{Membrane characterization}

The surface morphology of the adsorbent membrane before and after dye adsorption was thoroughly investigated by Scanning electron microscopy (SEM) (JEOL-6380LA ) and Atomic force microscopy (AFM) (Nanosurf EasyScan AFM). For AFM analysis, $10 \mu \mathrm{m}$ x $10 \mu \mathrm{m}$ of the membrane sample was scanned by tapping mode in air. The surface roughness was reported in terms of root mean square roughness. In order to confirm the adsorption of dye on membrane surface, elemental mapping and Energy Dispersive X-ray (EDX) analysis were carried out. For this study, the membrane was initially gold sputtered for conductivity. To understand the interactions between the membrane and dye, Fourier transform infrared spectra (FTIR) spectra of the membranes were recorded on Perkin Elmer Spectrum 100 equipped with Attenuated total reflectance (ATR) analyzer. The spectra was recorded in the working range $650-4000 \mathrm{~cm}^{-1}$.

\subsubsection{Dye Removal studies}

The dye removal capacity of SA/HEC/HA membrane was investigated in terms of variation in initial dye concentration, adsorbent dosage, $\mathrm{pH}$, time and temperature. All the experiments were carried out using batch-adsorption process on an orbital shaker at $27{ }^{\circ} \mathrm{C}$ and at $150 \mathrm{rpm}$. The experiments were performed at $\mathrm{pH} 7$ with adsorbent dosage of $0.3 \mathrm{~g}$ unless stated otherwise. After the completion of experiment, the absorbance of the supernatant dye solution was analyzed using Ultraviolet-visible (UV-Vis) spectrophotometer (Analytikjena Specord $\mathrm{S} 600)$. The absorbance of $\mathrm{MB}$ and $\mathrm{RhB}$ was measured at wavelength $665 \mathrm{~nm}$ and $554.5 \mathrm{~nm}$ respectively which was determined as by their $\lambda_{\max }$ value (Supporting information S1). A calibration plot of absorbance against concentration was used to determine the concentration of the dye solution. From the initial and final concentration, dye removal (\%) was calculated as

$$
\text { Dye Removal }(\%)=\left(1-\frac{C_{e}}{C_{0}}\right) \times 100 \ldots \ldots \ldots \ldots \text {........ } 1
$$

where, $C_{e}$ and $C_{0}$ are the equilibrium and initial dye concentrations in $\mathrm{mg} / \mathrm{L}$. The amount of dye adsorbed on the membrane was calculated as 


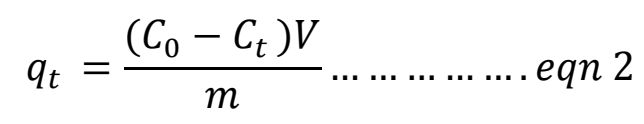

where, $q_{t}$ is the amount of dye adsorbed per unit mass of the adsorbent $(\mathrm{mg} / \mathrm{g}),{ }^{\prime} \mathrm{m}$ ' is the mass of the adsorbent $(\mathrm{g})$, ' $V$ ' is the volume of the dye solution $(\mathrm{L})$. As mentioned above, $C_{0}$ is the initial dye concentration and $C_{t}$ is the concentration at time $\mathrm{t},(\mathrm{mg} / \mathrm{L})$. All the experiments were performed in triplicate and the average value of $C_{e}$ and $q_{t}$ was considered for isotherm and kinetic studies. For time dependent kinetic studies, at given time intervals, aliquots of supernatant solution was extracted and analyzed for $\mathrm{MB}$ and $\mathrm{RhB}$ as described above.

\subsubsection{Membrane reusability}

The reusability of the adsorbent membrane was studied by performing desorption studies. For desorption experiment, dye adsorbed membrane was added to $0.1 \mathrm{M} \mathrm{HCl}$ solution taken in a $100 \mathrm{~mL}$ Erlenmeyer flask and was agitated on an orbital shaker at $150 \mathrm{rpm}$ for $5 \mathrm{~h}$ at $27^{\circ} \mathrm{C}$. After the specified time, membrane was thoroughly washed with distilled water until the $\mathrm{pH}$ of the solution was neutral. The dried membrane sample was subsequently subjected to second round of adsorption process. The adsorption-desorption cycle was repeated for four times to investigate the membrane reusability.

\section{Results and discussion}

For all the studies, desired amount of adsorbent was cut into small pieces of approximately $0.5 \mathrm{~cm}^{2}$. As stated earlier, the handling of the membrane became convenient because of the strong polypropylene support. Cutting of the membrane to smaller pieces ensured more surface of the membrane was available for dye adsorption.

The adsorbent membrane comprised of SA/HEC/HA film and a polypropylene support. Experiments performed on neat polypropylene support indicated that, it did not play any major role in the dye removal process. Hence, in order to study the effect of adsorbent dosage, the weight of the SA/HEC/HA film alone was decided to find out first. For this purpose, weight of neat polypropylene film was noted as $\mathrm{w}_{1}$. The membrane was weighed again after the deposition of the crosslinked adsorbent layer. This weight was noted as $\mathrm{w}_{2}$. The difference in weight was further used to calculate the actual weight of the adsorbing layer. Hence, when the overall adsorbent weighed $0.1 \mathrm{~g}$, only $0.02 \mathrm{~g}$ comprised of the SA/HEC/HA film. Similarly, for $0.2 \mathrm{~g}$ 
and $0.3 \mathrm{~g}, 0.05 \mathrm{~g}$ and $0.08 \mathrm{~g}$ respectively formed the active adsorbent layer. The calculations were done in triplicate to achieve accuracy.

\subsection{Point of zero charge of the membrane}

From Figure 2, $\mathrm{P}_{\mathrm{zc}}$ of the membrane was found out to be 3.56 (regression coefficient 0.99). The acidic nature of the surface must have been due to the presence of carboxylic and phenolic groups of HA, and acid groups of SA. The membrane, thus, was positively charged below 3.56, whereas above this $\mathrm{pH}$ value, it possessed negative charge. This implied that, adsorption of cation is favored when $\mathrm{pH}>\mathrm{P}_{\mathrm{zc}}$, and adsorption of anion is preferred when $\mathrm{pH}<\mathrm{P}_{\mathrm{zc}}$.

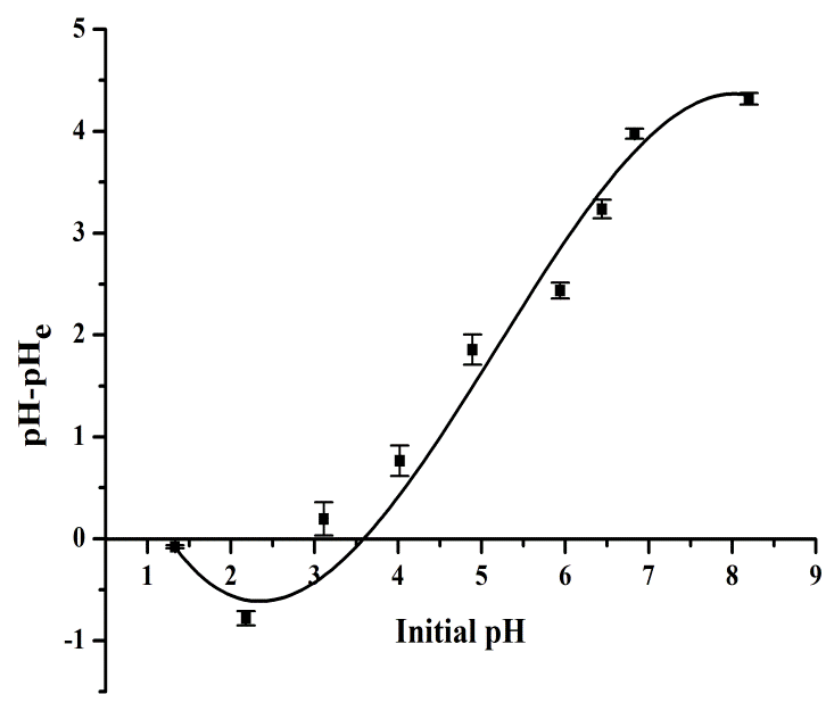

Figure 2 Point of zero charge of the membrane

\subsection{SEM and FTIR analysis}

SEM images of the surface of SA/HEC/HA membrane are shown in Figure 3. The membrane surface in the absence of dye (Figure 3A) appeared to be relatively smooth in comparison to the dye adsorbed membrane surface in Figure 3B and 3C. The surface of the membrane coupons adsorbed with dye was coarse and rough. This can be attributed to the dye aggregates formed on the membrane surface during adsorption process. This was further confirmed by an increase in the surface roughness for dye adsorbed membrane as recorded by AFM images (Supporting information S2) 

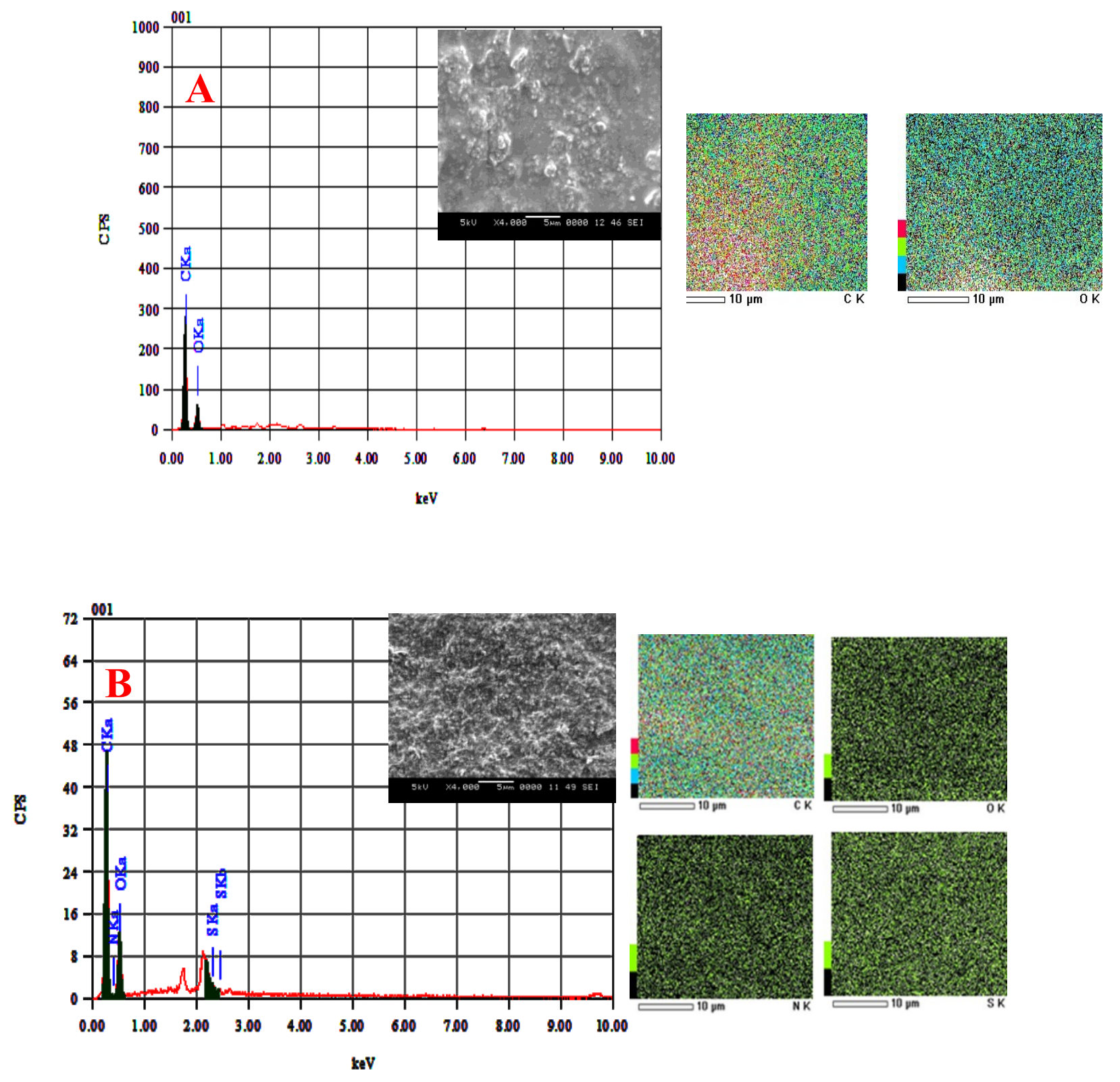

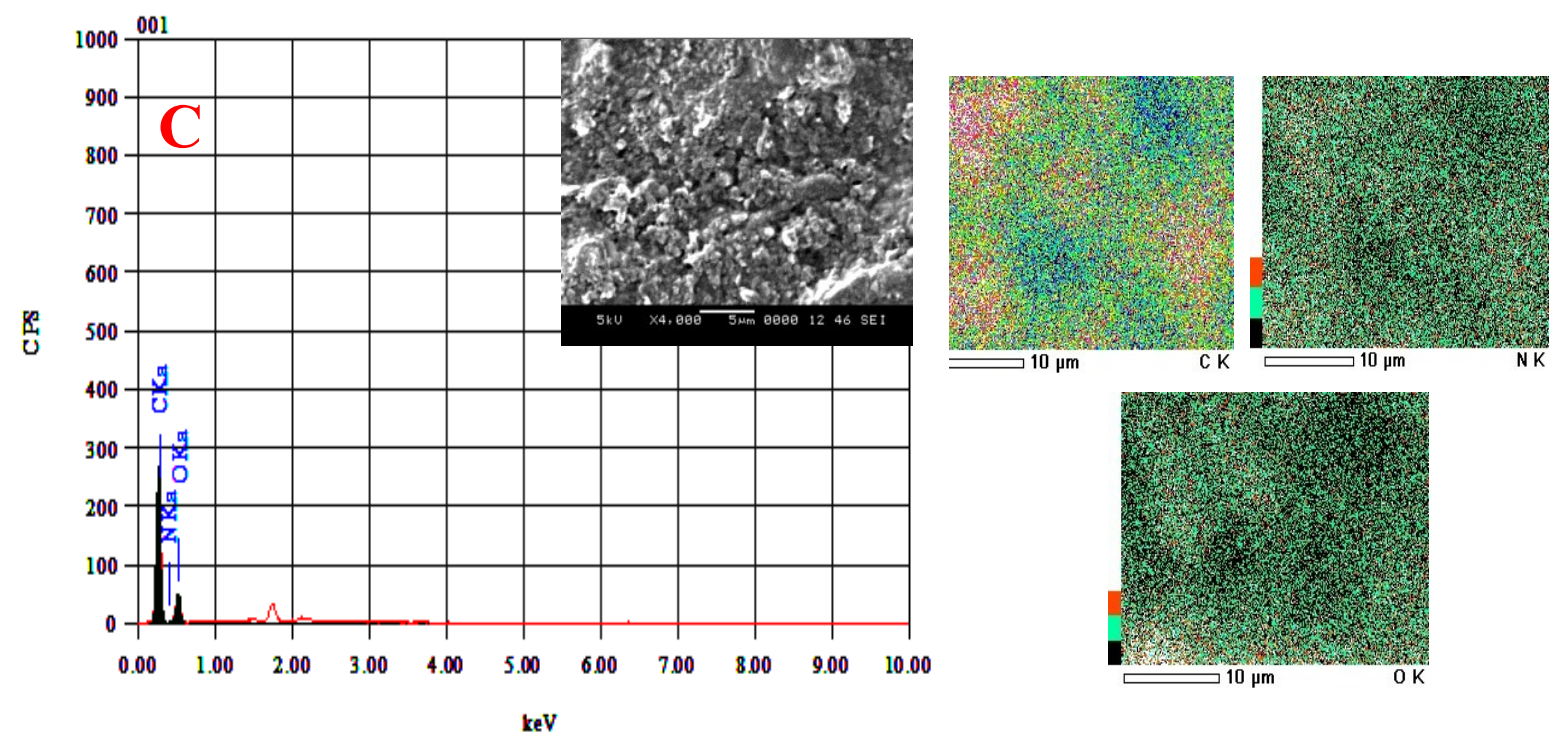

Figure 3 SEM, EDX and elemental mapping of A) SA/HEC/HA adsorbent membrane B) MB adsorbed membrane C) RhB adsorbed membrane

Dye adsorption was further confirmed by elemental mapping and EDX analysis. The presence of nitrogen and sulfur peak (the elements present in MB molecule) in the EDX spectra (Figure 3B) was indicative of MB adsorption on the membrane. A similar observation was made for $\mathrm{RhB}$ adsorbed membrane sample (Figure 3C), which primarily contained nitrogen in its molecular structure.

The FTIR spectra of the adsorbent membrane showcased characteristic peaks at $3367 \mathrm{~cm}^{-}$ ${ }^{1}$ (OH stretching frequency of carboxyl and phenol groups), $1586 \mathrm{~cm}^{-1}$ ( $\mathrm{C}=\mathrm{O}$ stretching of the conjugated carbonyl group), $1701 \mathrm{~cm}^{-1}(\mathrm{C}=\mathrm{O}$ stretch of carbonyl group in $\mathrm{SA})$ and $1115 \mathrm{~cm}^{-1}$ (C-O stretching frequency) (Figure 4). The spectra, with dye adsorbed on its surface exhibited decreased intensity of $\mathrm{OH}$ stretching frequency for $\mathrm{MB}$ and $\mathrm{RhB}$. This peculiar observation revealed electrostatic interaction between the carboxylate ions of the adsorbent with the cationic dye. Had some chemical changes (chemical bond formation) occurred during the adsorption, a very prominent change in the IR spectra of the dye adsorbed membrane would have been witnessed, which was not the case. By calculating the area under the $\mathrm{OH}$ peak, it was concluded that, nearly $40 \%$ of carboxylate ions of the membrane interacted with the dyes under consideration (Supporting information S3). The concentration of the dye on the membrane surface was too less to give strong peaks in the IR spectra. 


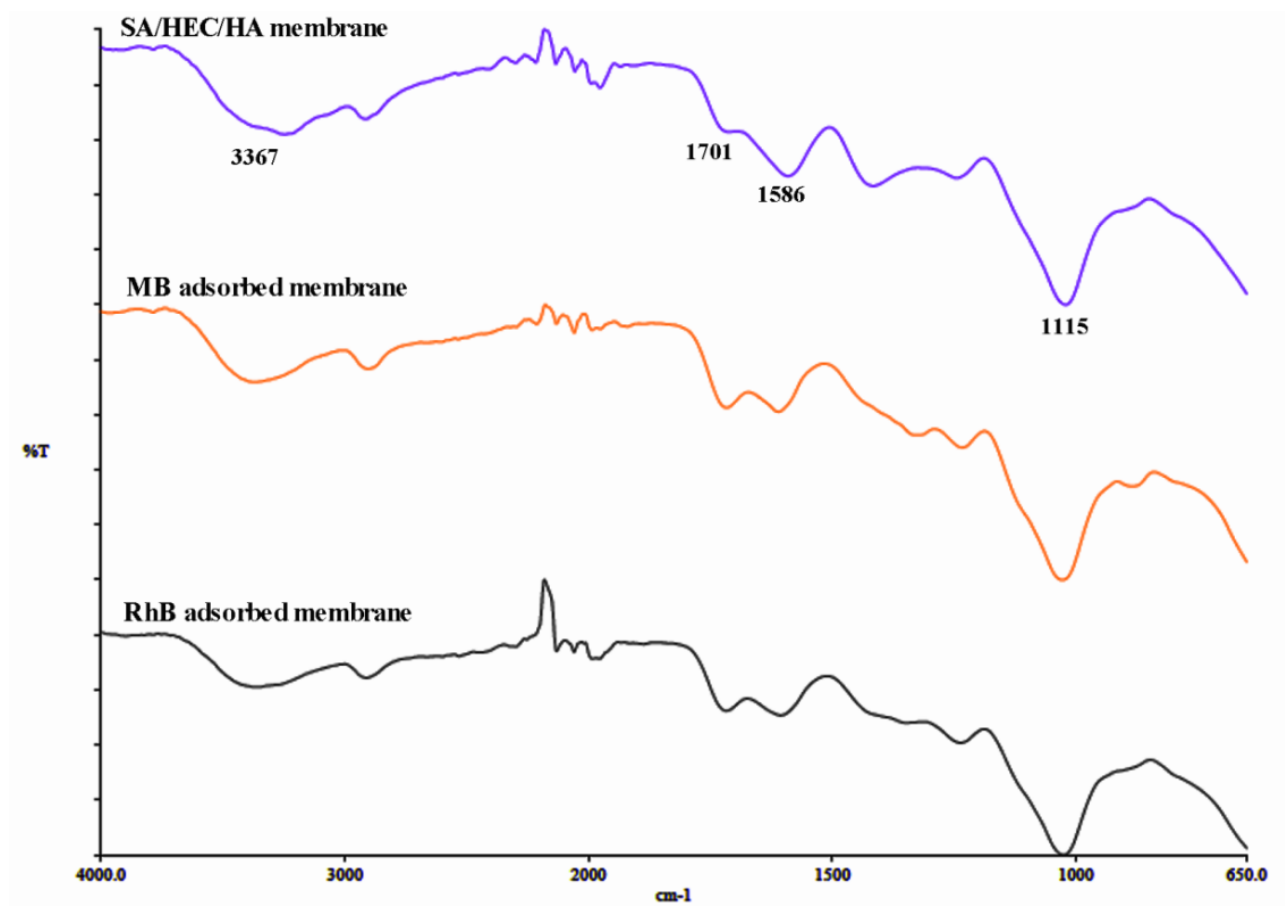

Figure 4 FTIR spectra of unadsorbed and dye adsorbed membrane samples

\subsection{Effect of initial dye concentration}

For this study, six different concentrations $(5,15,30,50,75,100 \mathrm{mg} / \mathrm{L})$ of $\mathrm{MB}$ and $\mathrm{RhB}$ were prepared at $\mathrm{pH} 7$ to which $0.3 \mathrm{~g}$ of the adsorbent membrane was added.
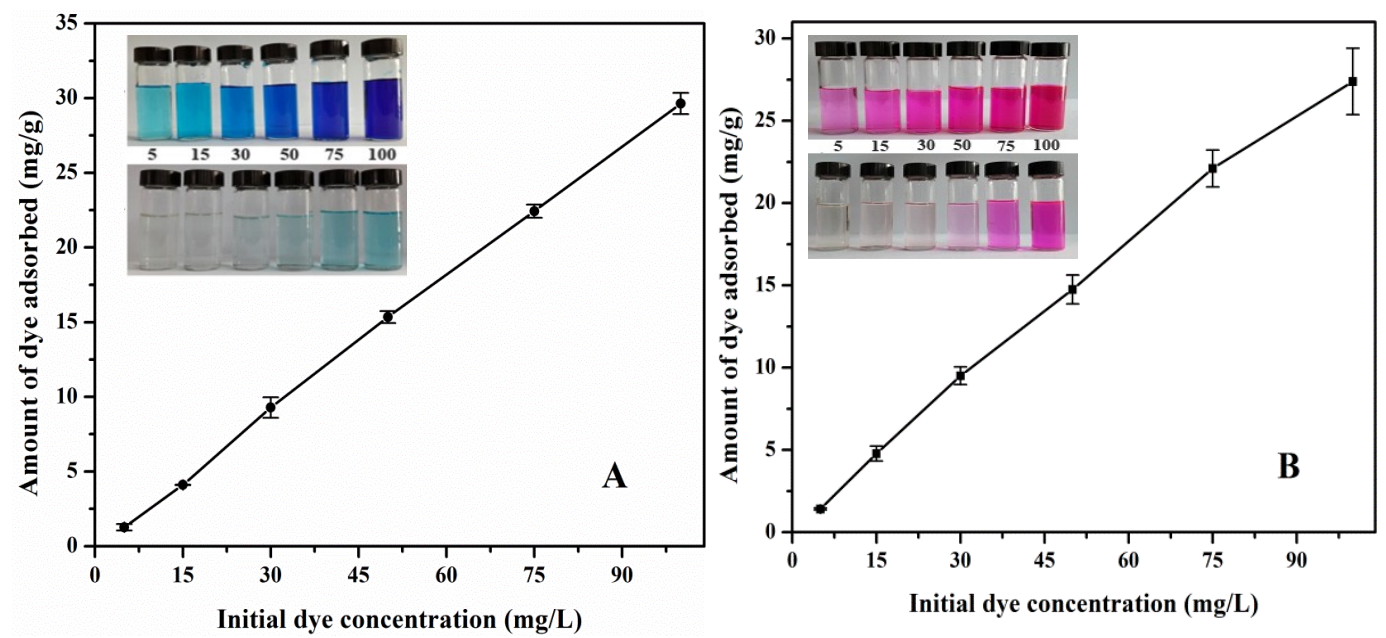

Figure 5 Effect of change in initial A) MB and B) RhB concentration on dye adsorption

The initial dye concentration plays a major role in governing the mass transfer resistance of dye molecules between the aqueous phase and the solid phase. The increase in dye concentration 
serves as a driving force to overcome this resistance, which in turn increases the probability of collision between the dye molecules and the adsorbent, thus leading to higher adsorption. ${ }^{23}$ This effect has been reflected in Figure 5, where it is observed that, with an increase in the initial dye concentration, the amount of dye adsorbed also increases. At $100 \mathrm{mg} / \mathrm{L}$ concentration, the maximum amount of dye adsorbed for $\mathrm{MB}$ and $\mathrm{RhB}$ was $30.14 \mathrm{mg} / \mathrm{g}$ and $28.81 \mathrm{mg} / \mathrm{g}$ respectively.

\subsection{Variation in adsorbent dosage}

The adsorbent dose strongly influences the amount of dye adsorbed. To investigate this effect, weighed amount of adsorbent was contacted with $25 \mathrm{~mL}$ of dye solution having initial concentration $50 \mathrm{mg} / \mathrm{L}$ and $100 \mathrm{mg} / \mathrm{L}$. From Figure 6, it was observed that, dye removal increased with increase in adsorbent dosage from $0.1 \mathrm{~g}$ to $0.3 \mathrm{~g}$. As the dosage increased, more number of adsorption sites were generated on the membrane surface which enabled more dye molecules to be adsorbed, hence resulting in higher removal. In addition to this, at neutral $\mathrm{pH}$ $\left(\mathrm{pH}>\mathrm{P}_{\mathrm{zc}}\right)$, the membrane was negatively charged due to deprotonation of the carboxylic groups on the membrane surface. With an increase in dosage, electrostatic interaction between the negatively charged membrane surface and cationic dye molecules was more pronounced. This combined effect led to higher $\mathrm{MB}$ and $\mathrm{RhB}$ removal at $0.3 \mathrm{~g}$. However, with the increase in adsorbent dosage, the dye uptake reduced from 58.03 to $15.02 \mathrm{mg} / \mathrm{g}$ in case of MB and 49.96 to $15.36 \mathrm{mg} / \mathrm{g}$ in case of $\mathrm{RhB}$ at $50 \mathrm{mg} / \mathrm{L}$. Higher number of unsaturated sites at higher adsorbent dose, decreased the adsorption density of the membrane. The amount of dye adsorbed per unit mass of adsorbent reduced significantly with increase in adsorbent mass which explains their lower $\mathrm{q}_{\mathrm{e}}$ values. ${ }^{24}$ 

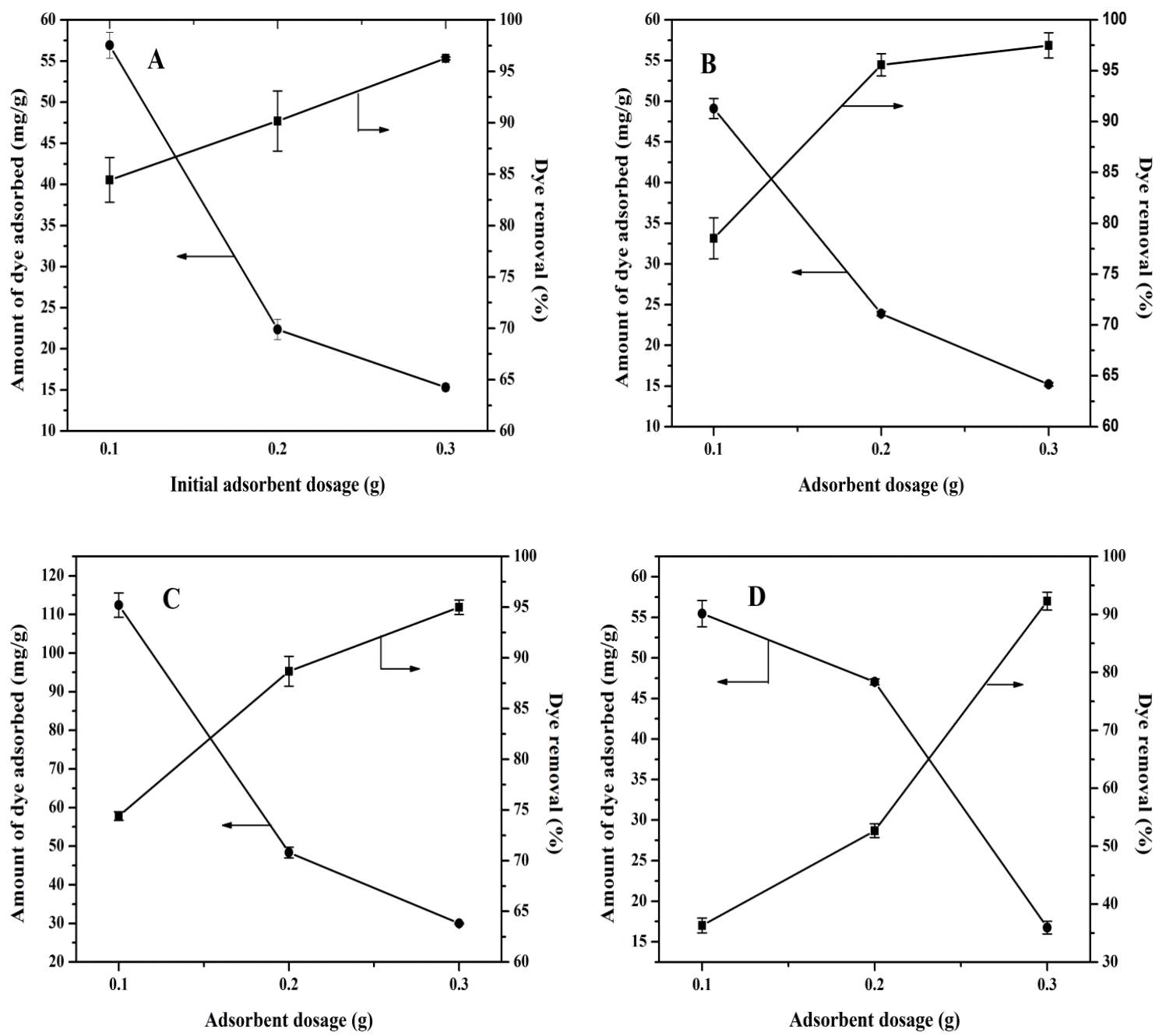

Figure 6 Effect of adsorbent dosage on A) MB and B) RhB removal at $50 \mathrm{mg} / \mathrm{L}$ dye concentration $\mathrm{C}$ ) $\mathrm{MB}$ and $\mathrm{D}) \mathrm{RhB}$ at $100 \mathrm{mg} / \mathrm{L}$ dye concentration respectively

\subsection{Effect of change in $\mathrm{pH}$}

Basic dyes exist in cationic form in aqueous solution. The $\mathrm{pH}$ of the solution influences the charge on the membrane which in turns governs the degree of adsorption of the dye on its surface. The $\mathrm{pH}$ also influences the degree of ionization of the dye molecules. Since, the membrane possesses charged surface containing carboxylic and phenolic groups, it shows different behavior in acidic and basic media. At lower $\mathrm{pH}$, i.e at $\mathrm{pH}<\mathrm{P}_{\mathrm{zc}}$, the cationic dye molecules are in competition with the hydrogen ions to interact with the adsorbent membrane. Moreover, the membrane becomes positively charged because of the protonation of carboxylic groups, in addition to the adsorbed $\mathrm{H}^{+}$ions on its surface, thus, repelling the incoming positively 
charged $\mathrm{MB}$ and $\mathrm{RhB}$ molecules. Owing to this combined effect, adsorption is low at $\mathrm{pH}<\mathrm{P}_{\mathrm{zc}}$. There is increase in the adsorption efficiency with increase in $\mathrm{pH}$ due to the fact that, at higher $\mathrm{pH}$, the adsorption sites get deprotonated making the membrane now negatively charged. The electrostatic forces of attraction are on highest par between the negatively charged membrane surface and positively charged dye molecule under such situation. An important observation in case of MB dye can be noted that, the adsorption efficiency is greater at $\mathrm{pH} 9$ than $\mathrm{pH} 7$ (Figure 7A). The explanation for the same can be as follows. The dissociation of carboxylic groups occur at $\mathrm{pH}>4$, whereas that of phenolic $\mathrm{OH}$ groups occur at $\mathrm{pH}>8 .^{25}$ This implied that, at $\mathrm{pH} 9$, both carboxylic and phenolic groups are completely dissociated making the adsorbent membrane more negative than that at $\mathrm{pH} 7$.

Unlike $\mathrm{MB}$, from Figure 7B, it is observed that $\mathrm{RhB}$ removal was less at $\mathrm{pH}$ 9. Literature suggests that, $\mathrm{RhB}$ in water exists in the zwitterionic form above $\mathrm{pH} 4$ (Figure 8). ${ }^{26}$ The existence of this zwitterionic form reduces the interaction between the negatively charged membrane surface and $\mathrm{RhB}$ dye which is reflected in the decreased dye rejection. Aggregation of $\mathrm{RhB}$ molecules at $\mathrm{pH}>4$ due to formation of zwitterions also hinders its entry into the membrane pores. ${ }^{11}$ At $\mathrm{pH} 1$, the protons present in the solution competed with $\mathrm{RhB}$ molecules to interact with the membrane, hence, showed least rejection
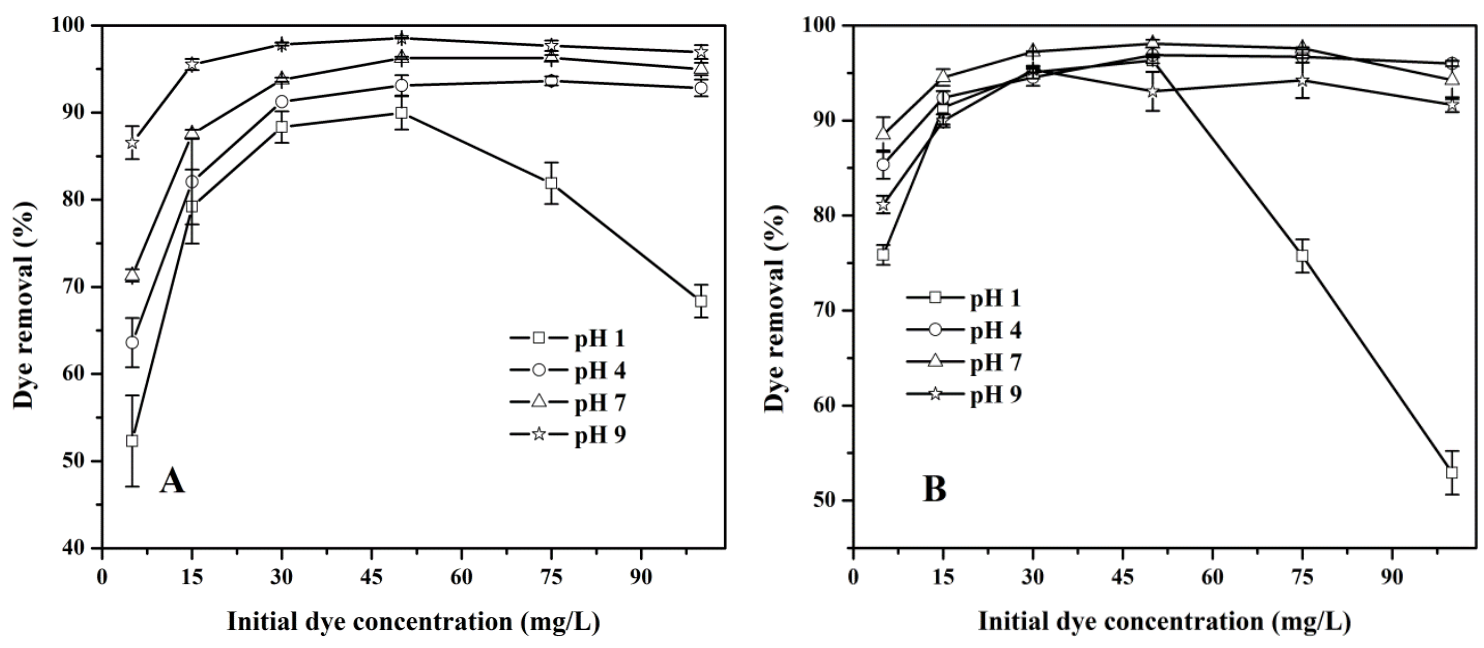

Figure 7 Effect of $\mathrm{pH}$ on dye removal capacity of $\mathrm{A}$ ) $\mathrm{MB}$ and $\mathrm{B}$ ) $\mathrm{RhB}$ 


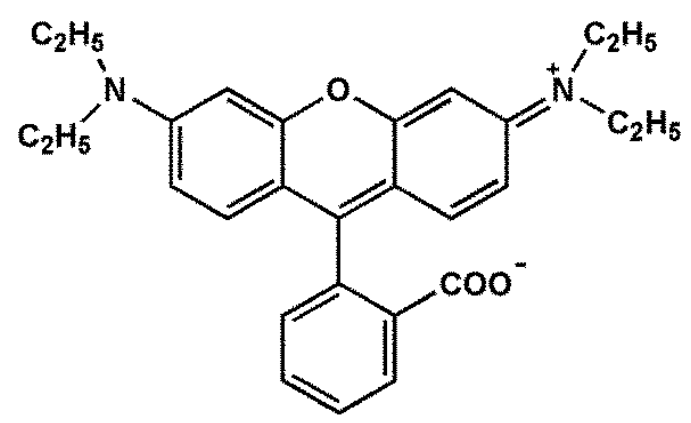

Figure 8 Zwitterionic form of $\mathrm{RhB}$

\subsection{Effect of time}

Figure 9 shows the plot of dye removal efficiency as a function of time. The plot indicates that, for both the dyes, major part of the removal process occurred in the early 40 to 50 $\min$.
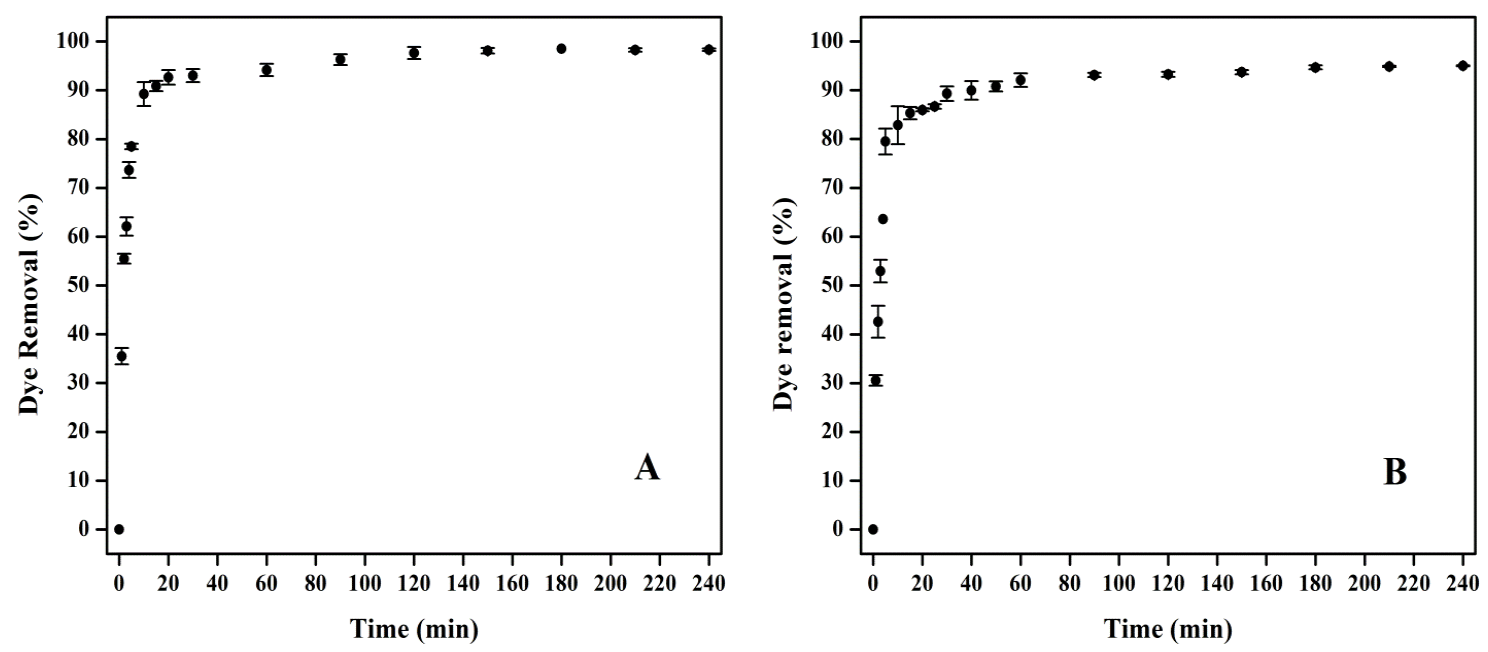

Figure 9 Dye removal efficiency as a function of time A) for MB B) RhB

In the initial $10 \mathrm{~min}$ of the adsorption process, nearly $80 \%$ of the dye was removed which indicated the adsorption efficiency of the SA/HEC/HA membrane. Equilibrium value of $96 \%$ was achieved for $\mathrm{MB}$ after $120 \mathrm{~min}$, whereas, for $\mathrm{RhB}$ an equilibrium value of $94.9 \%$ was obtained after 180 min. This suggested rapid uptake of MB molecules than RhB molecules. Higher removal capacity at initial stages was the result of presence of excess vacant sites on the surface which made it easier for the dye molecules to be occupied easily. With advancement in time, it became difficult for dye molecules to get adsorbed as the surface was now covered partially/completely. This resulted in slower removal of the dye from the bulk solution. Constant 
value was reached when the amount of dye adsorbed onto the adsorbent was in a state of dynamic equilibrium with the amount of dye desorbed. ${ }^{27}$

\subsection{Adsorption Isotherms}

Information regarding how the adsorbate molecules distribute themselves between the liquid and solid phase is provided by the adsorption isotherms. ${ }^{28}$ The dye adsorption onto the membrane was studied by fitting the adsorption data into four isotherm models, namely Langmuir, Fruendlich, Temkin and Dubinin-Radushkevich equations.

\subsubsection{Langmuir Isotherm}

Langmuir isotherm is based on the assumption that, all the adsorbent sites are equivalent and there is no interaction between the adsorbate molecules formed as a monolayer. The linear form of Langmuir equation is given as

$$
\frac{C_{e}}{q_{e}}=\frac{1}{b q_{\max }}+\frac{C_{e}}{q_{\max }} \ldots \ldots \ldots \ldots \ldots \text { eqn } 3
$$

where, $C_{e}(\mathrm{mg} / \mathrm{L})$ and $q_{e}(\mathrm{mg} / \mathrm{g})$ are the concentration and amount of dye adsorbed at equilibrium; ' $\mathrm{b}$ ' is the Langmuir coefficient $(\mathrm{L} / \mathrm{mg})$ related to the affinity of binding site; and $q_{\max }$ is the maximum adsorption capacity per unit mass of the adsorbent $(\mathrm{mg} / \mathrm{g})$.

\subsubsection{Freundlich Isotherm}

Freundlich isotherm is applied to heterogeneous surfaces based on the assumption that the adsorption sites are not equivalent. The linear form of Freundlich equation is given as

$$
\ln q_{e}=\ln K_{F}+\frac{1}{n} \ln C_{e} \ldots \ldots \ldots \ldots \ldots \text { eqn } 4
$$

where, $C_{e}$ and $q_{e}$ have their usual meaning as mentioned above, $K_{F}\left(\mathrm{mg}^{1-1 / \mathrm{n}} \mathrm{L}^{1 / \mathrm{n}} \mathrm{g}^{-1}\right)$ and ' $n$ ' are Freundlich coefficients related to adsorption capacity and adsorption intensity respectively. If reciprocal of Freundlich coefficient $(1 / \mathrm{n})<1$, it is considered as an indication of favorable adsorption.

\subsubsection{Temkin isotherm}

Temkin model takes into consideration the effects of interaction between adsorbate, and gives an idea about the heat of the adsorption process. ${ }^{11}$ It takes the form 


$$
q_{e}=B \ln A+B \ln C_{e} \ldots \ldots \ldots \ldots \ldots \text { eqn } 5
$$

where,

$$
B=\frac{R T}{b}
$$

where, $\mathrm{R}$ is the universal gas constant $\left(8.314 \mathrm{Jmol}^{-1} \mathrm{~K}^{-1}\right)$; $\mathrm{B}$ and $\mathrm{b}\left(\mathrm{Jmol}^{-1}\right)$ are Temkin coefficients and $A(\mathrm{~L} / \mathrm{mg})$ is the equilibrium binding constant corresponding to maximum binding energy.

\subsubsection{Dubinin-Radushkevich isotherm}

Dubinin-Radushkevich isotherm helps in determining whether an adsorption process is physical, ion exchange or chemical type. It takes the form

$$
\ln q_{e}=\ln q_{\max }-K_{D} \varepsilon^{2} \ldots \ldots \ldots \ldots \text { eqn } 6
$$

where, $\mathrm{K}_{\mathrm{D}}\left(\mathrm{mol}^{2} / \mathrm{J}^{2}\right)$ is the D-R constant which is related to adsorption energy; ' $\varepsilon$ ' is the Polanyi potential $(\mathrm{J} / \mathrm{mol})$ calculated as

$$
\varepsilon=R T \ln \left(1+\frac{1}{C_{e}}\right)
$$

' $\mathrm{R}$ ' is the gas constant $\left(\mathrm{Jmol}^{-1} \mathrm{~K}^{-1}\right), \mathrm{T}$ is the absolute temperature $(\mathrm{K})$ and $C_{e}(\mathrm{mg} / \mathrm{L})$ is the dye concentration at equilibrium. Th D-R constant is used to calculate mean free energy of adsorption, ' $E$ ' as

$$
E=\frac{1}{\sqrt{2 K_{D}}}
$$

Depending on the value of $E$, the type of adsorption process can be identified. If the value of $E$ is $<8 \mathrm{~kJ} / \mathrm{mol}$, physical adsorption prevails. If value lies between $8 \mathrm{~kJ} / \mathrm{mol}-16 \mathrm{~kJ} / \mathrm{mol}$, the adsorption may be ion exchange adsorption; when, $E>16 \mathrm{~kJ} / \mathrm{mol}$ chemical adsorption may explain the adsorption type.

The adsorption isotherm results of all the models have been tabulated in Table 1. From the table, it was concluded that, the adsorption data followed Langmuir and DubininRadushkevich isotherm more satisfactorily than the other isotherms. The regression coefficients for Freundlich and Temkin isotherm were very low. The mean free energy of adsorption $(E)$ 
calculated from D-R model was $<8 \mathrm{~kJ} / \mathrm{mol}$ for both the dyes, indicating physical adsorption existed between the dye molecules and the adsorbent membrane. From Langmuir plot, $\mathrm{q}_{\max }$ for $\mathrm{MB}$ and $\mathrm{RhB}$ was calculated to be $20.83 \mathrm{mg} / \mathrm{g}$ and $18.81 \mathrm{mg} / \mathrm{g}$ respectively.

Table 1 Isotherm parameters for MB and RhB adsorption on SA/HEC/HA membrane

\begin{tabular}{|c|l|l|}
\hline Dye & $\mathrm{MB}$ & $\mathrm{RhB}$ \\
\hline $\begin{array}{c}\text { Langmuir Isotherm } \\
\mathrm{q}_{\max }\end{array}$ & $20.83(\mathrm{mg} / \mathrm{g})$ & $18.814(\mathrm{mg} / \mathrm{g})$ \\
$\mathrm{b}$ & $0.171(\mathrm{~L} / \mathrm{mg})$ & $0.293(\mathrm{~L} / \mathrm{mg})$ \\
$\mathrm{R}^{2}$ & 0.95 & 0.96 \\
\hline Freundlich Isotherm & & \\
$1 / \mathrm{n}$ & 0.95 & 0.485 \\
$\mathrm{~K}_{\mathrm{F}}$ & 1.404 & 4.11 \\
$\mathrm{R}^{2}$ & 0.517 & 0.55 \\
\hline $\mathrm{B}$ & & \\
$\mathrm{A}$ & 7.62 & 3.744 \\
$\mathrm{R}^{2}$ & $0.819(\mathrm{~L} / \mathrm{mg})$ & $4.58(\mathrm{~L} / \mathrm{mg})$ \\
$\mathrm{K}_{\mathrm{D}}$ & 0.827 & 0.787 \\
$\mathrm{E}$ & $3.548 \times 10^{-6}\left(\mathrm{~mol}^{2} / \mathrm{J}^{2}\right)$ & $6.02 \times 10^{-7}\left(\mathrm{~mol}^{2} / \mathrm{J}^{2}\right)$ \\
$\mathrm{R}^{2}$ & $0.375 \mathrm{~kJ} / \mathrm{mol}$ & $0.91 \mathrm{~kJ} / \mathrm{mol}$ \\
\hline Dubinin-Radushkevich Isotherm & 0.954 & 0.967 \\
\hline
\end{tabular}

\subsection{Kinetic modeling of dye adsorption process}

Understanding the kinetics of an adsorption process is essential to predict the designing of sorption systems in industries. ${ }^{29}$ Rate of the adsorption process depends upon the nature and properties of the adsorbent, and the experimental conditions. The progress of the dye adsorption was examined by fitting the experimental data using six different kinetic models. A high regression coefficient value $\left(\mathrm{R}^{2}\right)$ (approaching unity), indicated the effectiveness of the model in describing the kinetics of dye adsorption. The results have been summarized in Table 2 .

3.7.1 Pseudo first order kinetic /Lagergren equation is expressed as

$$
\log \left(q_{e}-q_{t}\right)=\log q_{e}-\frac{k_{1} t}{2.303} \ldots \ldots \ldots \ldots \text { eqn } 7
$$


where, $q_{e}$ is the amount of dye adsorbed at equilibrium time $(\mathrm{mg} / \mathrm{g}), q_{t}$ is the amount of dye adsorbed at time $t(\mathrm{mg} / \mathrm{g})$ and $k_{1}$ is the first order rate constant $\left(\mathrm{min}^{-1}\right)$. The rate constant and $q_{e}$ values was determined from the slope and intercept of the plot, $\log \left(q_{e}-q_{t}\right)$ as a function of time $t$. Lagergren's first order kinetic equation is usually applicable for the initial 30 to $50 \mathrm{~min}$ of the adsorption process. ${ }^{30}$ It is not suitable for the entire contact time of the adsorption process. ${ }^{31}$ The model showcased considerable deviation of the experimental values from the theoretical values, giving a $\mathrm{R}^{2}$ value of only 0.786 for $\mathrm{MB}$ and 0.96 for $\mathrm{RhB}$ (Figure 10 ). Moreover, the amount of dye adsorbed calculated from the graph did not agree well with the experimental values, indicating pseudo-first order model was not best suited to represent the dye adsorption process.

3.7.2 Simple first order kinetic model is expressed as

$$
\log C_{t}=\frac{k_{1 \prime}}{2.303} t+\log C_{0} \ldots \ldots \ldots \ldots \text { eqn } 8
$$

where, $\mathrm{C}_{t}$ and $\mathrm{C}_{0}$ are the dye concentrations at time $\mathrm{t}$ and time $\mathrm{t}=0 . k_{1^{\prime}}$ is the rate constant $\left(\mathrm{min}^{-1}\right)$ obtained from the graph represented by the above equation. Since, the concentration of dye decreased with progress in time, the slope of the graph was negative giving negative rate constant value (Figure 10). Also, the regression coefficient was least for this model amongst the studied models, suggesting the non-applicability of this model to the adsorption data.

\subsubsection{Pseudo-second order kinetic equation is given as}

$$
\frac{t}{q_{t}}=\frac{1}{k_{2} q_{e}^{2}}+\frac{t}{q_{e}} \ldots \ldots \ldots \ldots \text {.....eqn } 9
$$

where, again $q_{e}$ and $q_{t}$ are the amount of dye adsorbed at equilibrium time and specific time respectively $(\mathrm{mg} / \mathrm{g}), k_{2}$ is the second order rate constant $(\mathrm{g} / \mathrm{mg}$ min) evaluated from the intercept of the plot $\mathrm{t} / \mathrm{q}_{\mathrm{t}}$ as a function of time. For most of the adsorbate-adsorbent systems, particularly when the adsorbate is a pollutant, the rate of the reaction is best represented by second order kinetic model. ${ }^{32}$ The pseudo-second order rate was developed by Ho to describe chemisorption involving valency forces between the adsorbent and adsorbate as covalent forces or ion exchange. ${ }^{33}$ It enables to find out the adsorption capacity, the rate constant and the initial rate of adsorption without knowing any parameter in advance. The correlation coefficient $\left(\mathrm{R}^{2}\right)$ for the linear plot of $\left(t / q_{t}\right)$ versus $t$ was closer to unity $(>0.99)$ for both the dyes (Figure 10). Moreover, 
the calculated $q_{e}$ value was in good agreement with the experimentally determined $q_{e}$ value. This suggested that the pseudo-second order kinetic model best explained the kinetics of MB and RhB adsorption on SA/HEC/HA membrane.

3.7.4 Ritchie's second order kinetic model is expressed as

$$
\frac{q_{e}}{q_{e}-q_{t}}=1+k_{2}, t \ldots \ldots \ldots \ldots \text { eqn } 10
$$

where, $k_{2}$ is the rate constant $\left(\mathrm{min}^{-1}\right)$ and can be obtained by plotting $q_{e} /\left(q_{e-} q_{t}\right)$ versus $t$. Ritchie proposed this model as an alternative to Elovich model on the assumption that, adsorption rate depends solely on the fraction of unoccupied sites at any time t. ${ }^{34}$ The investigation on the current adsorbent-adsorbate revealed that, the fitting of this model was not suitable to represent the kinetics of the adsorption system (Table 2).

\subsubsection{Intraparticle diffusion model}

The mechanism of the transport of dye molecules to the membrane involves intraparticle diffusion process which was studied using Webber and Moris plot ${ }^{35}$ given as

$$
q_{t}=k_{i d} t^{0.5}+c \ldots \ldots \ldots \ldots \text { eqn } 11
$$

where, $k_{i d}$ is the intraparticle diffusion rate constant $\left(\mathrm{mg} . \mathrm{g}^{-1} \mathrm{~min}^{-0.5}\right)$ obtained from the slope of linear part of the graph of $q_{t}$ versus $t^{0.5}$. The rate controlling step in the adsorption process may be governed by one or more than one of the following steps (i) boundary layer diffusion which is due to external surface adsorption of dye molecules (ii) intraparticle diffusion explaining the gradual adsorption process and (iii) final equilibrium stage. ${ }^{36}$ As observed from Figure 10, it is evident that the dye adsorption on the membrane occurred in three steps as mentioned above. The first part of the graph, showed a steep increase in $q_{t}$ value indicating fast diffusion of dye molecules from bulk solution to the external boundary of the adsorbent. The second part of the curve was the rate limiting step involving diffusion from the boundary layer to the interior or the active sites of the adsorbent. The final plateau region was due to very slow adsorption rate at equilibrium. It is known that, if the plot $q_{t}$ versus $t^{0.5}$ passes through the origin, then, only intraparticle diffusion is the rate limiting process. However, in the current investigation, presence of the intercept proved the thickness of the boundary layer; larger the intercept greater is the 
boundary effect. ${ }^{37}$ Thus, for MB and RhB adsorption onto the membrane, intraparticle diffusion and surface adsorption are the rate-limiting steps.

\subsubsection{Elovich Model}

In recent years, Elovich model is used to describe the kinetics of adsorption of pollutants from aqueous solutions. ${ }^{33}$ Elovich model is applied to heterogeneous adsorbing systems involving chemisorption with the assumption that the adsorption rate decreases with increase in time due to increased covering of the surface. ${ }^{27,} 38$ Simplified Elovich equation by applying boundary conditions is given as

$$
q_{t}=\frac{1}{\beta} \ln (\alpha \beta)+\frac{1}{\beta} \ln (t) \ldots \ldots \ldots \ldots \text { eqn } 12
$$

where, $q_{t}$ has its usual meaning, $\alpha$ is the initial rate of adsorption $(\mathrm{mg} / \mathrm{g} \cdot \mathrm{min})$ and $\beta(\mathrm{g} / \mathrm{mg})$ is the desorption constant related to the activation energy of chemisorption, and indicates the number of sites available for adsorption. ${ }^{39}$

Table 2 Adsorption kinetic parameters of $\mathrm{MB}$ and $\mathrm{RhB}$ on $\mathrm{SA} / \mathrm{HEC} / \mathrm{HA}$ membrane

\begin{tabular}{|c|c|c|}
\hline & Methylene blue & Rhodamine B \\
\hline$q_{e, \text { experimental }}$ & $15.39(\mathrm{mg} / \mathrm{g})$ & $14.839(\mathrm{mg} / \mathrm{g})$ \\
\hline Experimental parameters & \multicolumn{2}{|c|}{$\mathrm{C}_{0}=50 \mathrm{mg} / \mathrm{L}, \mathrm{pH} 7, \mathrm{~T}=27{ }^{\circ} \mathrm{C}$} \\
\hline Pseudo-first order kinetic model & & \\
\hline$q_{e, \text { calculated }}$ & $2.28(\mathrm{mg} / \mathrm{g})$ & $3.14(\mathrm{mg} / \mathrm{g})$ \\
\hline$k_{1}$ & $3.3 \times 10^{-2}\left(\mathrm{~min}^{-1}\right)$ & $3.9 \times 10^{-2}\left(\mathrm{~min}^{-1}\right)$ \\
\hline $\mathrm{R}^{2}$ & 0.786 & 0.964 \\
\hline Simple first order model & & \\
\hline$k_{1}^{\prime}$ & $-1.1 \times 10^{-2}\left(\mathrm{~min}^{-1}\right)$ & $-1.9 \times 10^{-3}\left(\mathrm{~min}^{-1}\right)$ \\
\hline $\mathrm{R}^{2}$ & 0.75 & 0.873 \\
\hline Pseudo-second order kinetic model & & \\
\hline$q_{e, \text { calculated }}$ & $15.625(\mathrm{mg} / \mathrm{g})$ & $14.97(\mathrm{mg} / \mathrm{g})$ \\
\hline$k_{2}$ & $4.04 \times 10^{-2}(\mathrm{~g} / \mathrm{mg} \min )$ & $3.17 \times 10^{-2}(\mathrm{~g} / \mathrm{mg} \mathrm{min})$ \\
\hline $\mathrm{R}^{2}$ & 0.9996 & 0.9997 \\
\hline $\begin{array}{l}\text { Ritchie's second order kinetic model } \\
\qquad k_{2^{\prime}}\end{array}$ & $0.489\left(\mathrm{~min}^{-1}\right)$ & $0.555\left(\mathrm{~min}^{-1}\right)$ \\
\hline
\end{tabular}




\begin{tabular}{|c|c|c|}
$\mathrm{R}^{2}$ & 0.912 & 0.925 \\
\hline Intraparticle diffusion model & & \\
$k_{\text {id }}$ & $0.1908\left(\mathrm{mg} \mathrm{g}^{-1} \mathrm{~min}^{-0.5}\right)$ & $0.3574\left(\mathrm{mg} \mathrm{g}^{-1} \mathrm{~min}^{-0.5}\right)$ \\
Intercept c & 13.46 & 11.88 \\
$\mathrm{R}^{2}$ & 0.9587 & 0.9457 \\
\hline Elovich Model & 0.95 & 0.934 \\
$\mathrm{R}^{2}$ & $1.74(\mathrm{~g} / \mathrm{mg})$ & $1.183(\mathrm{~g} / \mathrm{mg})$ \\
$\alpha$ & $1.99 \times 10^{9}$ & $3.21 \times 10^{5}$ \\
\hline
\end{tabular}

From Table 2, it was observed that the fitting of the Elovich model was satisfactory with regression coefficient 0.95 and 0.934 for $\mathrm{MB}$ and $\mathrm{RhB}$ respectively. The initial rate of adsorption $(\alpha)$ was very high for $\mathrm{MB}$ than $\mathrm{RhB}$.
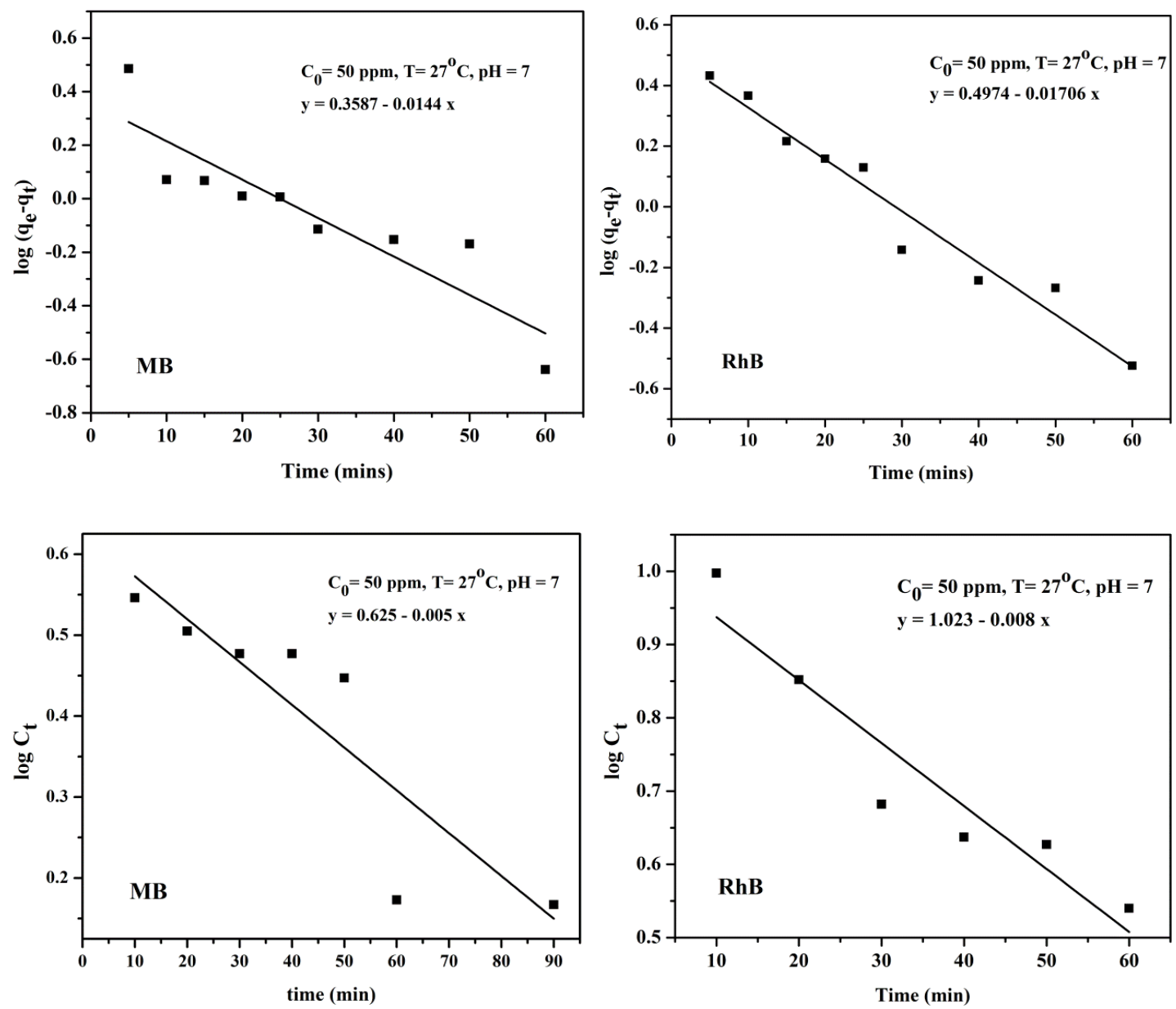

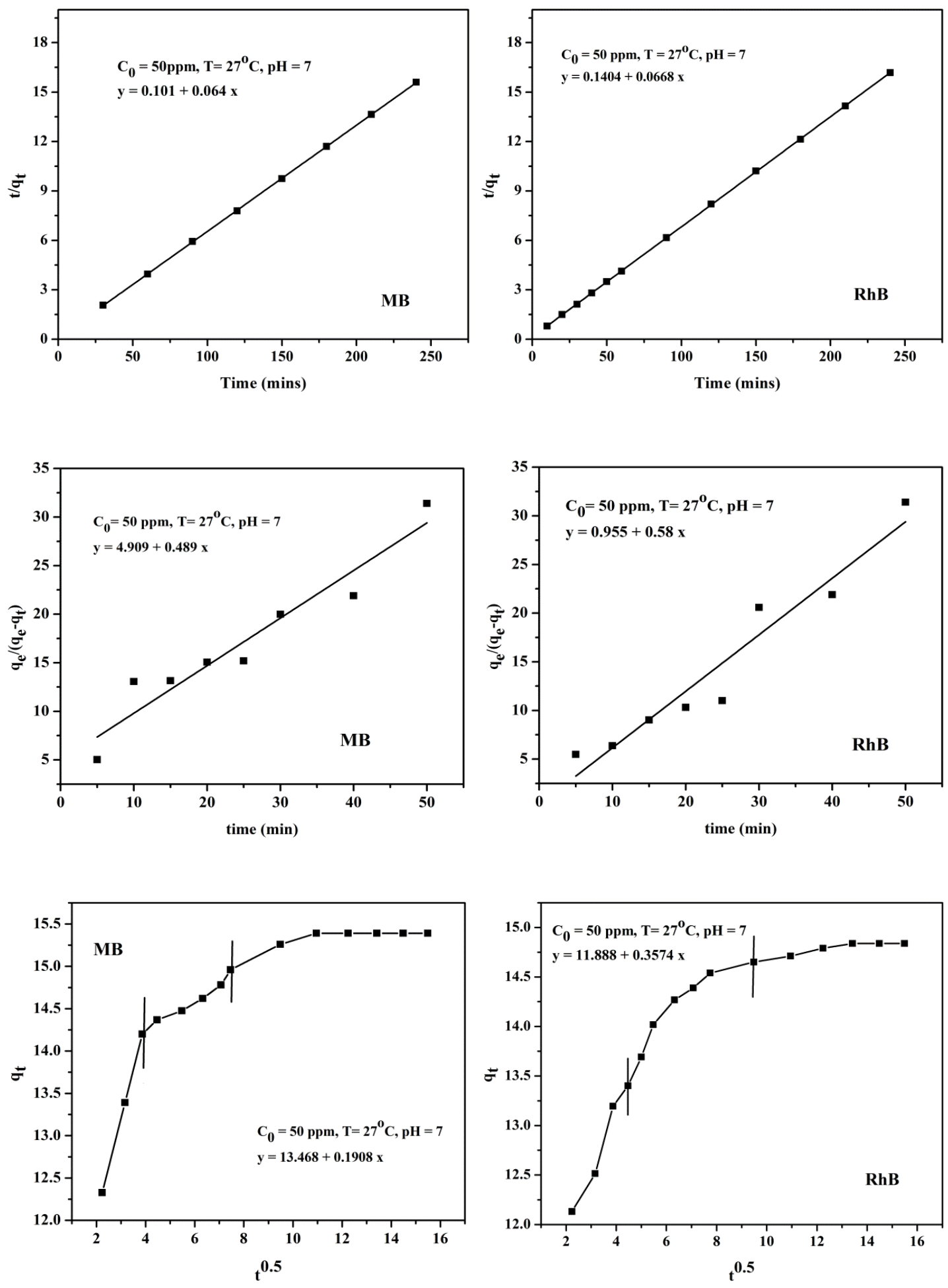

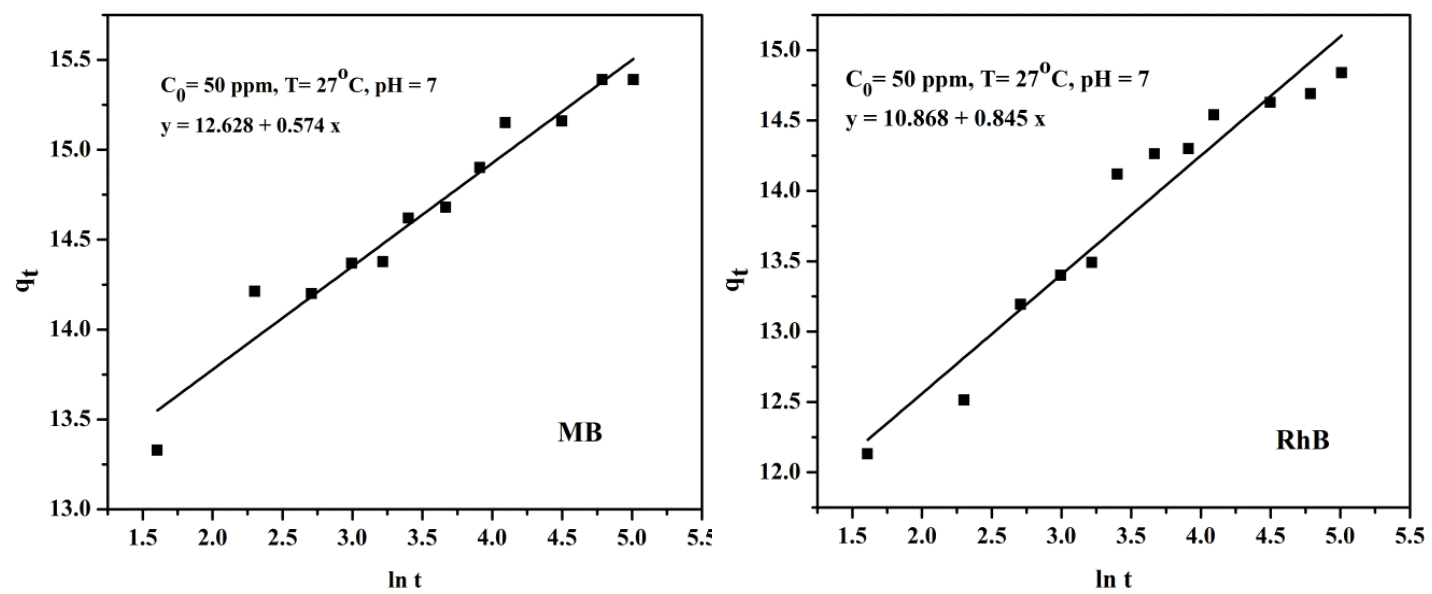

Figure 10 Kinetic modeling of MB and RhB dyes on SA/HEC/HA membrane

Amongst all the models, the pseudo-second order kinetic model best explained the adsorption dynamics of the dye-membrane system.

\subsection{Effect of temperature}

As observed from Figure 11, an increase in adsorption rate with elevation in temperature was confirmed. This indicated that, the adsorption process was endothermic in nature. The supplied heat energy helped the dye molecules in overcoming the activation barrier to attach themselves to the adsorbent membrane. The intraparticle diffusion rate of the dye into the membrane pores also increased with increase in temperature.
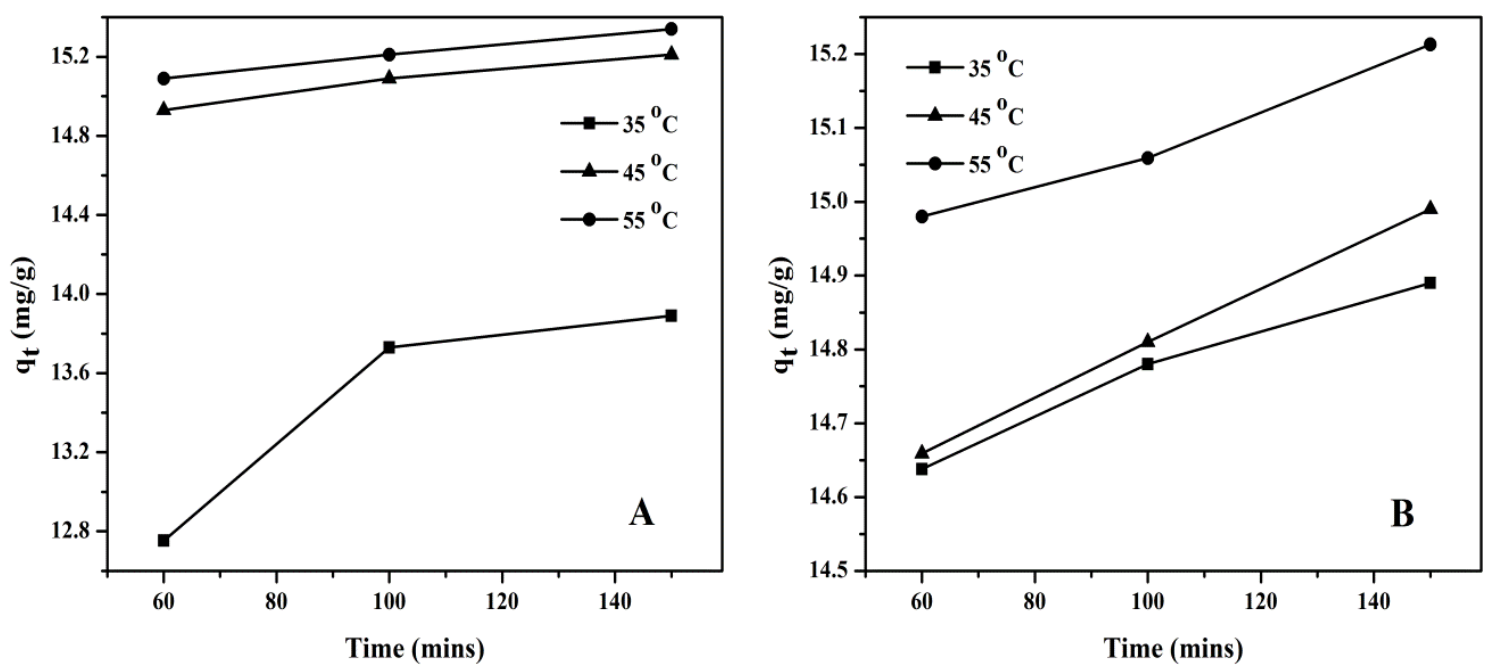

Figure 11 Effect of variation tin temperature on dye adsorption A) MB B) RhB 


\subsection{Thermodynamic parameters}

The thermodynamic parameters $\Delta \mathrm{H}^{\circ}, \Delta \mathrm{S}^{\circ}$ and $\Delta \mathrm{G}^{\circ}$ determine the heat change, feasibility and spontaneity of a particular adsorption process. These thermodynamic parameters were determined using the Van't Hoff equation ${ }^{10}$

$$
\begin{gathered}
\ln K=\frac{\Delta S^{\circ}}{R}-\frac{\Delta H^{\circ}}{R T} \ldots \ldots \ldots \ldots \ldots \ldots \text { eqn } 13 \\
\Delta G^{\circ}=-R T \ln K \ldots \ldots \ldots \ldots \ldots \text { eqn } 14
\end{gathered}
$$

where, $K=m\left(q_{e} / C_{e}\right)$ is the distribution coefficient, ' $\mathrm{m}$ ' is the mass of adsorbent $(\mathrm{g} / \mathrm{L}), \Delta \mathrm{S}^{\circ}$ is the change in entropy $\left(\mathrm{Jmol}^{-1} \mathrm{~K}^{-1}\right), \Delta \mathrm{H}^{\circ}$ is the the enthalpy of activation $(\mathrm{J} / \mathrm{mol}), \Delta \mathrm{G}^{\circ}$ is Gibbs energy $(\mathrm{J} / \mathrm{mol})$, ' $\mathrm{R}$ ' is the gas constant, and ' $\mathrm{T}$ ' is the temperature $(\mathrm{K})$. Entropy and enthalpy of activation calculated from the slope and intercept of the Van't Hoff plot (plot not given), has been given in Table 3. The positive values of $\Delta \mathrm{H}^{\circ}$ confirms the adsorption of dye on the membrane was endothermic in nature. The positive value of $\Delta \mathrm{S}^{\circ}$ suggested better affinity of dye molecules towards the membrane and increased disorderness at solid-liquid interface. The feasibility and spontaneity of the adsorption was proved by the negative values of $\Delta \mathrm{G}^{\circ}$. Also, decrease in $\Delta \mathrm{G}^{\circ}$ value with rising temperature suggested higher rate of adsorption at higher temperature. It is reported that, if the value of $\Delta \mathrm{G}^{\circ}$ ranges between 0 and $-20 \mathrm{~kJ} / \mathrm{mol}$, electrostatic interactions are prevalent between the adsorption sites and the adsorbing ions (physical adsorption). ${ }^{7,}{ }^{40}$ The values of $\Delta \mathrm{G}^{\circ}$ (Table 3) suggest adsorption of $\mathrm{MB}$ and $\mathrm{RhB}$ onto the membrane is a physisorption process.

The energy of activation, $E_{a}$ was calculated from the following equation

$$
\log \frac{k_{2}}{k_{1}}=\frac{E_{a}}{2.303 \times R}\left(\frac{T_{2}-T_{1}}{T_{2} T_{1}}\right) \ldots \ldots \ldots \ldots \text { eqn } 15
$$

where, $\mathrm{k}_{1}$ and $\mathrm{k}_{2}$ are the pseudo-second order rate constants at temperature $\mathrm{T}_{1}$ and $\mathrm{T}_{2}$ respectively

\begin{tabular}{|c|c|c|c|c|c|c|c|}
\hline \multirow{2}{*}{ Dye } & $\Delta \mathrm{H}^{\circ}$ & & \multicolumn{3}{|c|}{$\Delta \mathrm{G}^{\circ}(\mathrm{kJ} / \mathrm{mol})$} & $\mathrm{E}_{\mathrm{a}}$ & $\mathrm{D}^{2}$ \\
\hline & $(\mathrm{kJ} / \mathrm{mol})$ & $(\mathrm{kJ} / \mathrm{mol} . \mathrm{K})$ & $308 \mathrm{~K}$ & $318 \mathrm{~K}$ & $328 \mathrm{~K}$ & $(\mathrm{~kJ} / \mathrm{mol})$ & \\
\hline
\end{tabular}
(Supporting information S4).

Table 3 Values of thermodynamic parameters for $\mathrm{MB}$ and $\mathrm{RhB}$ adsorption onto the membrane 


\begin{tabular}{|l|c|c|ccc|c|c|}
\hline Methylene blue & 46.603 & 0.176 & -7.39 & -9.55 & -10.905 & 7.042 & 0.97 \\
Rhodamine B & 25.306 & 0.107 & -7.703 & -8.67 & -9.841 & 8.77 & 0.99 \\
\hline
\end{tabular}

\subsection{Membrane reusability}

Facile and efficient regeneration capacity of a process is an indicative parameter of environmentally as well as economically viable process. The reusability of the prepared membranes for dye adsorption was investigated by running four cycles of adsorption and desorption. There was no significant reduction in the efficiency of the adsorbent even after four cycles (Figure 12). The results obtained were quantitative where the efficiency of the adsorbent was nearly $98 \%$ for both the dyes. This implied that, the adsorbent could be regenerated by simple acid treatment.

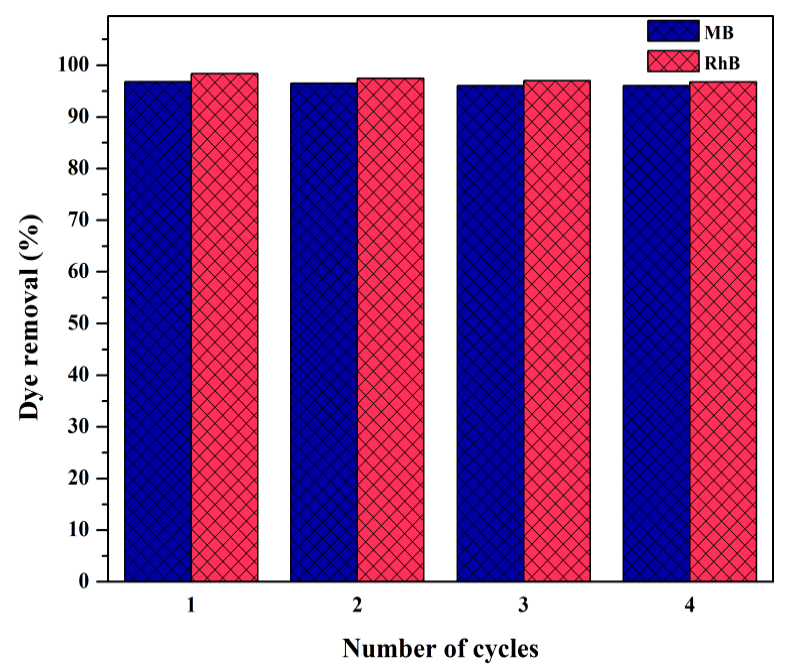

Figure 12 Dye removal for four adsorption cycles after $0.1 \mathrm{M} \mathrm{HCl}$ treatment

Table $4 \mathrm{MB}$ and $\mathrm{RhB}$ removal with other reported systems under optimal conditions

\begin{tabular}{|c|c|c|}
\hline Adsorbent & MB & RhB \\
\hline Modified bentonite clay ${ }^{41}$ & $99.9 \%, 149.4 \mathrm{mg} / \mathrm{g}$ & $83 \%, 155.2 \mathrm{mg} / \mathrm{g}$ \\
\hline $\operatorname{Red~Mud~}^{42}$ & $75 \%, 19.55 \mathrm{mg} / \mathrm{g}$ & $92.5 \%, 5.5 \mathrm{mg} / \mathrm{g}$ \\
\hline Baggasse fly ash ${ }^{12}$ & $70 \%$ & $69 \%$ \\
\hline Gum ghatti $/ \mathrm{Fe}_{3} \mathrm{O}_{4}$ nanocomposite ${ }^{10}$ & - & $98 \%, 654.87 \mathrm{mg} / \mathrm{g}$ \\
\hline
\end{tabular}




\begin{tabular}{|c|c|c|}
\hline Kaolinite $^{43}$ & - & $83 \%, 46.08 \mathrm{mg} / \mathrm{g}$ \\
\hline Sago waste activated carbon ${ }^{44}$ & - & $91 \%, 16.12 \mathrm{mg} / \mathrm{g}$ \\
\hline Fly ash $^{45}$ & - & $54 \%, 10 \mathrm{mg} / \mathrm{g}$ \\
\hline Orange peel ${ }^{46}$ & & $67.5 \%, 3.22 \mathrm{mg} / \mathrm{g}$ \\
\hline Graphene oxide/calcium alginate composite ${ }^{7}$ & $92.7 \%, 181.81 \mathrm{mg} / \mathrm{g}$ & - \\
\hline $\mathrm{Fe}_{3} \mathrm{O}_{4}$ core shell nanoparticles ${ }^{47}$ & $90 \%, 44.38 \mathrm{mg} / \mathrm{g}$ & - \\
\hline Spent coffee ground ${ }^{48}$ & $>98 \%, 18.7 \mathrm{mg} / \mathrm{g}$ & - \\
\hline Wheat shells ${ }^{49}$ & $>95 \%, 16.56 \mathrm{mg} / \mathrm{g}$ & - \\
\hline Coir pith carbon ${ }^{50}$ & $>99 \%, 5.87 \mathrm{mg} / \mathrm{g}$ & - \\
\hline Fly ash (sonochemically treated) ${ }^{51}$ & $4.48 \mathrm{mg} / \mathrm{g}$ & - \\
\hline Sludge ash ${ }^{52}$ & $1.87 \mathrm{mg} / \mathrm{g}$ & - \\
\hline Current work & $>98 \%, 20.83 \mathrm{mg} / \mathrm{g}$ & $>98 \%, 18.81 \mathrm{mg} / \mathrm{g}$ \\
\hline
\end{tabular}

\section{Conclusions}

Humic acid immobilized sodium alginate-hydroxyethyl cellulose adsorbent membrane was prepared to remove methylene blue and rhodamine B from aqueous solution. The zero point charge study revealed the anionic nature of the membrane surface above $3.56 \mathrm{pH}$. Methylene blue and rhodamine B being cationic in nature, interacted electrostatically with the negatively charged adsorbent membrane. The amount of dye adsorbed amplified with increase in initial dye concentration and temperature due to the higher probability of collisions between the dye molecules. However, adsorption decreased with increasing adsorbent dosage due to decrease in adsorption density. Membranes were capable of removing more than $80 \%$ dye during the initial $10 \mathrm{~min}$ due to the presence of excess of vacant sites. $\mathrm{pH}$ studies indicated maximum removal of 98.5\% at $\mathrm{pH} 9$ for methylene blue, and 97\% for rhodamine $\mathrm{B}$ at $\mathrm{pH} 7$. This was in accordance with the extent of interactions prevailing between the membrane and the dye at a given $\mathrm{pH}$. Dubinin-Radushkevich model and pseudo second order kinetic model best explained the adsorption equilibrium and kinetics of the dye-membrane system. The energy of adsorption calculated from D-R model and Gibbs free energy of activation indicated that, the dye adsorption occurred on the membrane surface by simple physisorption process. The intraparticle diffusion model suggested surface adsorption and intraparticle diffusion as the rate-limiting steps. 
Regeneration of the adsorbent was possible by simple acid treatment, and its efficiency remained mostly unaltered even after four adsorption cycles. Thus, a simple and efficient biopolymeric membrane was utilized in recovering clear water from dye contaminated aqueous stream.

Acknowledgements AMI thank Prof. Swapan Bhattacharya, Director, National Institute of Technology Karnataka, Surathkal, India for providing the research facilities and encouragements.

\section{REFERENCES}

(1) Gurses, A.; Dogar, C.; Yalcin, M.; Acikyildiz, M.; Bayrak, R.; Karaca, S. The adsorption kinetics of the cationic dye, methylene blue, onto clay. J. Hazard. Mater. 2006, 131 (1-3), $217-$ 228.

(2) Karim, Z.; Mathew, A. P.; Grahn, M.; Mouzon, J.; Oksman, K. Nanoporous membranes with cellulose nanocrystals as functional entity in chitosan: Removal of dyes from water. Carbohydr. Polym. 2014, 112, 668-676.

(3) Ashiq, M. N.; Najam-Ul-Haq, M.; Amanat, T.; Saba, A.; Qureshi, A. M.; Nadeem, M. Removal of methylene blue from aqueous solution using acid/base treated rice husk as an adsorbent. Desalination and Water Treatment 2012, 49 (1-3), 376-383.

(4) Yagub, M. T.; Sen, T. K.; Afroze, S.; Ang, H. M. Dye and its removal from aqueous solution by adsorption: a review. Adv. Colloid Interface Sci. 2014, 209, 172-84.

(5) Deka, J. R.; Liu, C. L.; Wang, T. H.; Chang, W. C.; Kao, H. M. Synthesis of highly phosphonic acid functionalized benzene-bridged periodic mesoporous organosilicas for use as efficient dye adsorbents. J. Hazard. Mater. 2014, 278, 539-50.

(6) Jain, N.; Bhargava, A.; Panwar, J. Enhanced photocatalytic degradation of methylene blue using biologically synthesized "protein-capped" $\mathrm{ZnO}$ nanoparticles. Chem. Eng. J. (Lausanne) 2014, 243, 549-555.

(7) Li, Y.; Du, Q.; Liu, T.; Sun, J.; Wang, Y.; Wu, S.; Wang, Z.; Xia, Y.; Xia, L. Methylene blue adsorption on graphene oxide/calcium alginate composites. Carbohydr. Polym. 2013, 95 (1), 501-507.

(8) Zhou, K.; Zhang, Q.; Wang, B.; Liu, J.; Wen, P.; Gui, Z.; Hu, Y. The integrated utilization of typical clays in removal of organic dyes and polymer nanocomposites. Journal of Cleaner Production 2014, 81, 281-289.

(9) Gürses, A.; Hassani, A.; Kıranşan, M.; Açışl1, Ö.; Karaca, S. Removal of methylene blue from aqueous solution using by untreated lignite as potential low-cost adsorbent: Kinetic, thermodynamic and equilibrium approach. Journal of Water Process Engineering 2014, 2, 1021.

(10) Mittal, H.; Mishra, S. B. Gum ghatti and $\mathrm{Fe}_{3} \mathrm{O}_{4}$ magnetic nanoparticles based nanocomposites for the effective adsorption of rhodamine B. Carbohydr. Polym. 2014, 101, 1255-1264.

(11) Bhattacharyya, K. G.; SenGupta, S.; Sarma, G. K. Interactions of the dye, Rhodamine B with kaolinite and montmorillonite in water. Appl. Clay Sci. 2014, 99, 7-17.

(12) Gupta, V. K.; Mohan, D.; Sharma, S.; Sharma, M. Removal of basic dyes (Rhodamine B and Methylene Blue) from aqueous solutions using bagasse fly ash. Sep. Sci. Technol. 2000, 35 (13), 2097-2113. 
(13) Vinod, V. P.; Anirudhan, T. S. Adsorption behaviour of basic dyes on the humic acid immobilized pillared clay. Water, Air, Soil Pollut. 2003, 150, 193-217.

(14) Sedláček, P.; Smilek, J.; Klučáková, M. How the interactions with humic acids affect the mobility of ionic dyes in hydrogels -2 . Non-stationary diffusion experiments. React. Funct. Polym. 2014, 75, 41-50.

(15) Deng, S.; Bai, R. B. Aminated polyacrylonitrile fibers for humic acid adsorption behaviors and mechanisms. Environ. Sci. Technol. 2003, 37, 5799-5805.

(16) Liu, J.-f.; Zhao, Z.-s.; Jiang, G.-b. Coating $\mathrm{Fe}_{3} \mathrm{O}_{4}$ magnetic nanoparticles with humic acid for high efficient removal of heavy metals in water. Environ. Sci. Technol. 2008, 42 (18), 69496954.

(17) Tan, X. L.; Wang, X. K.; Geckeis, H.; Rabung, T. H. Sorption of Eu(III) on humic acid or fulvic acid bound to hydrous alumina studied by SEM-EDS, XPS, TRLFS, and batch techniques. Environ. Sci. Technol. 2008, 42 (17), 6532-6537.

(18) Abdul, A. S.; Gibson, T. L.; Rai, D. N. Use of humic acid solution to remove organic contaminants from hydrogeologic systems. Environ. Sci. Technol. 1990, 24 (3), 328-333.

(19) Li, H.; Sheng, G.; Teppen, B. J.; Johnston, C. T.; Boyd, S. A. Sorption and desorption of pesticides by clay minerals and humic acid-clay complexes. Soil Sci. Soc. Am. J. 2003, 67 (1), 122-131.

(20) Vijaya Kumar Naidu, B.; Krishna Rao, K. S. V.; Aminabhavi, T. M. Pervaporation separation of water+1,4-dioxane and water+tetrahydrofuran mixtures using sodium alginate and its blend membranes with hydroxyethylcellulose-A comparative study. J. Membr. Sci. 2005, 260 (1-2), 131-141.

(21) Chen, J. H.; Liu, Q. L.; Hu, S. R.; Ni, J. C.; He, Y. S. Adsorption mechanism of Cu(II) ions from aqueous solution by glutaraldehyde crosslinked humic acid-immobilized sodium alginate porous membrane adsorbent. Chem. Eng. J. (Lausanne) 2011, 173 (2), 511-519.

(22) Chen, J. H.; Ni, J. C.; Liu, Q. L.; Li, S. X. Adsorption behavior of Cd(II) ions on humic acid-immobilized sodium alginate and hydroxyl ethyl cellulose blending porous composite membrane adsorbent. Desalination 2012, 285, 54-61.

(23) Baral, S. S.; Das, N.; Roy Chaudhury, G.; Das, S. N. A preliminary study on the adsorptive removal of $\mathrm{Cr}(\mathrm{VI})$ using seaweed, Hydrilla verticillata. J. Hazard. Mater. 2009, 171 (1-3), 358-69.

(24) Vadivelan, V.; Kumar, K. V. Equilibrium, kinetics, mechanism, and process design for the sorption of methylene blue onto rice husk. J. Colloid Interface Sci. 2005, 286 (1), 90-100.

(25) Dong, C.; Chen, W.; Liu, C.; Liu, Y.; Liu, H. Synthesis of magnetic chitosan nanoparticle and its adsorption property for humic acid from aqueous solution. Colloids Surf., A 2014, 446, 179-189.

(26) Peng, L.; Qin, P.; Lei, M.; Zeng, Q.; Song, H.; Yang, J.; Shao, J.; Liao, B.; Gu, J. Modifying $\mathrm{Fe}_{3} \mathrm{O}_{4}$ nanoparticles with humic acid for removal of Rhodamine $\mathrm{B}$ in water. $J$. Hazard. Mater. 2012, 209-210, 193-8.

(27) Dotto, G. L.; Pinto, L. A. A. Adsorption of food dyes onto chitosan: Optimization process and kinetic. Carbohydr. Polym. 2011, 84 (1), 231-238.

(28) Natarajan, T. S.; Bajaj, H. C.; Tayade, R. J. Preferential adsorption behavior of methylene blue dye onto surface hydroxyl group enriched $\mathrm{TiO}_{2}$ nanotube and its photocatalytic regeneration. J. Colloid Interface Sci. 2014, 433, 104-114.

(29) Subramanyam, B.; Das, A. Study of the adsorption of phenol by two soils based on kinetic and isotherm modeling analyses. Desalination 2009, 249 (3), 914-921. 
(30) Wang, Y.; Mu, Y.; Zhao, Q.-B.; Yu, H.-Q. Isotherms, kinetics and thermodynamics of dye biosorption by anaerobic sludge. Sep. Purif. Technol. 2006, 50 (1), 1-7.

(31) Otero, M.; Rozada, F.; Calvo, L. F.; García, A. I.; Morán, A. Kinetic and equilibrium modelling of the methylene blue removal from solution by adsorbent materials produced from sewage sludges. Biochem. Eng. J. 2003, 15 (1), 59-68.

(32) Zhang, X.; Zhang, P.; Wu, Z.; Zhang, L.; Zeng, G.; Zhou, C. Adsorption of methylene blue onto humic acid-coated $\mathrm{Fe}_{3} \mathrm{O}_{4}$ nanoparticles. Colloids Surf., A 2013, 435, 85-90.

(33) Ho, Y. S. Review of second-order models for adsorption systems. J. Hazard. Mater. 2006, 136 (3), 681-689.

(34) Ritchie, A. G. Alternative to the Elovich equation for the kinetics of adsorption of gases on solids. J. Chem. Soc., Faraday Trans. 1977, 73 (0), 1650-1653.

(35) Nasuha, N.; Hameed, B. H.; Din, A. T. Rejected tea as a potential low-cost adsorbent for the removal of methylene blue. J. Hazard. Mater. 2010, 175 (1-3), 126-32.

(36) Cheung, W. H.; Szeto, Y. S.; McKay, G. Intraparticle diffusion processes during acid dye adsorption onto chitosan. Bioresour. Technol. 2007, 98 (15), 2897-904.

(37) Dogan, M.; Alkan, M.; Turkyilmaz, A.; Ozdemir, Y. Kinetics and mechanism of removal of methylene blue by adsorption onto perlite. J. Hazard. Mater. 2004, 109 (1-3), 141-8.

(38) Zhao, G.; Li, J.; Wang, X. Kinetic and thermodynamic study of 1-naphthol adsorption from aqueous solution to sulfonated graphene nanosheets. Chem. Eng. J. (Lausanne) 2011, 173 (1), 185-190.

(39) Jayakumar, R.; Rajasimman, M.; Karthikeyan, C. Sorption of hexavalent chromium from aqueous solution using marine green algae Halimeda gracilis: Optimization, equilibrium, kinetic, thermodynamic and desorption studies. Journal of Environmental Chemical Engineering 2014, 2 (3), 1261-1274.

(40) Weng, C. H.; Lin, Y. T.; Tzeng, T. W. Removal of methylene blue from aqueous solution by adsorption onto pineapple leaf powder. J. Hazard. Mater. 2009, 170 (1), 417-24.

(41) Anirudhan, T. S.; Ramachandran, M. Adsorptive removal of basic dyes from aqueous solutions by surfactant modified bentonite clay (organoclay): Kinetic and competitive adsorption isotherm. Process Saf. Environ. Prot. 2015, 95, 215-225.

(42) Gupta, V. K.; Suhas; Ali, I.; Saini, V. K. Removal of rhodamine B, fast green, and methylene blue from wastewater using red mud, an aluminum industry waste. Ind. Eng. Chem. Res. 2004, 43, 1740-1747.

(43) Khan, T. A.; Dahiya, S.; Ali, I. Use of kaolinite as adsorbent: Equilibrium, dynamics and thermodynamic studies on the adsorption of Rhodamine B from aqueous solution. Appl. Clay Sci. 2012, 69, 58-66.

(44) Kadirvelu, K.; Karthika, C.; Vennilamani, N.; Pattabhi, S. Activated carbon from industrial solid waste as an adsorbent for the removal of Rhodamine-B from aqueous solution: Kinetic and equilibrium studies. Chemosphere 2005, 60 (8), 1009-1017.

(45) Chang, S. H.; Wang, K. S.; Li, H. C.; Wey, M. Y.; Chou, J. D. Enhancement of Rhodamine B removal by low-cost fly ash sorption with Fenton pre-oxidation. J. Hazard. Mater. 2009, 172 (2-3), 1131-6.

(46) Namasivayam, C.; Muniasamy, N.; Gayatri, K.; Rani, M.; Ranganathan, K. Removal of dyes from aqueous solutions by cellulosic waste orange peel. Bioresour. Technol. 1996, 57, 3743.

(47) Zhang, Z.; Kong, J. Novel magnetic $\mathrm{Fe}_{3} \mathrm{O}_{4} @ \mathrm{C}$ nanoparticles as adsorbents for removal of organic dyes from aqueous solution. J. Hazard. Mater. 2011, 193 (0), 325-329. 
(48) Franca, A. S.; Oliveira, L. S.; Ferreira, M. E. Kinetics and equilibrium studies of methylene blue adsorption by spent coffee grounds. Desalination 2009, 249 (1), 267-272.

(49) Bulut, Y.; Aydın, H. A kinetics and thermodynamics study of methylene blue adsorption on wheat shells. Desalination 2006, 194 (1-3), 259-267.

(50) Kavitha, D.; Namasivayam, C. Experimental and kinetic studies on methylene blue adsorption by coir pith carbon. Bioresour. Technol. 2007, 98 (1), 14-21.

(51) Wang, S.; Zhu, Z. H. Sonochemical treatment of fly ash for dye removal from wastewater. J. Hazard. Mater. 2005, 126 (1-3), 91-5.

(52) Weng, C.-H.; Pan, Y.-F. Adsorption characteristics of methylene blue from aqueous solution by sludge ash. Colloids and Surfaces A: Physicochemical and Engineering Aspects 2006, 274 (1-3), 154-162.

\section{LIST OF FIGURES}

Figure 1 Structure of A) methylene blue and B) rhodamine B

Figure 2 Point of zero charge of the membrane

Figure 3 SEM, EDX and elemental mapping of A) SA/HEC/HA adsorbent membrane B) MB adsorbed membrane C) RhB adsorbed membrane

Figure 4 FTIR spectra of unadsorbed and dye adsorbed membrane samples

Figure 5 Effect of change in initial A) MB and B) RhB concentration on dye adsorption

Figure 6 Effect of adsorbent dosage on $\mathrm{A}$ ) $\mathrm{MB}$ and $\mathrm{B}$ ) $\mathrm{RhB}$ removal at $50 \mathrm{mg} / \mathrm{L}$ dye concentration C) $\mathrm{MB}$ and $\mathrm{D}) \mathrm{RhB}$ at $100 \mathrm{mg} / \mathrm{L}$ dye concentration respectively

Figure 7 Effect of $\mathrm{pH}$ on dye removal capacity of A) $\mathrm{MB}$ and $\mathrm{B}$ ) $\mathrm{RhB}$

Figure 8 Zwitterionic form of $\mathrm{RhB}$

Figure 9 Dye removal efficiency as a function of time for A) MB B) $R h B$

Figure 10 Kinetic modeling of $\mathrm{MB}$ and $\mathrm{RhB}$ dyes on $\mathrm{SA} / \mathrm{HEC} / \mathrm{HA}$ membrane

Figure 11 Effect of variation in temperature on dye adsorption A) MB B) $R h B$

Figure 12 Dye removal for four adsorption cycles after $0.1 \mathrm{M} \mathrm{HCl}$ treatment

\section{LIST OF TABLES}

Table 1 Isotherm parameters for $\mathrm{MB}$ and RhB adsorption on SA/HEC/HA membrane

Table 2 Adsorption kinetic parameters of $\mathrm{MB}$ and $\mathrm{RhB}$ on $\mathrm{SA} / \mathrm{HEC} / \mathrm{HA}$ membrane

Table 3 Values of thermodynamic parameters for $\mathrm{MB}$ and $\mathrm{RhB}$ adsorption onto the membrane

Table $4 \mathrm{MB}$ and $\mathrm{RhB}$ removal with other reported systems under optimal conditions 
